\title{
A Review on Homogeneous Charge Compression Ignition and Low Temperature Combustion by Optical Diagnostics
}

\author{
Chao Jin ${ }^{1}$ and Zunqing Zheng ${ }^{2}$ \\ ${ }^{1}$ School of Environmental Science and Engineering, Tianjin University, Tianjin 300072, China \\ ${ }^{2}$ State Key Laboratory of Engines, Tianjin University, Tianjin 300072, China \\ Correspondence should be addressed to Zunqing Zheng; zhengzunqing@tju.edu.cn
}

Received 13 January 2015; Revised 18 May 2015; Accepted 20 May 2015

Academic Editor: João Paulo Leal

Copyright (c) 2015 C. Jin and Z. Zheng. This is an open access article distributed under the Creative Commons Attribution License, which permits unrestricted use, distribution, and reproduction in any medium, provided the original work is properly cited.

\begin{abstract}
Optical diagnostics is an effective method to understand the physical and chemical reaction processes in homogeneous charge compression ignition (HCCI) and low temperature combustion (LTC) modes. Based on optical diagnostics, the true process on mixing, combustion, and emissions can be seen directly. In this paper, the mixing process by port-injection and direct-injection are reviewed firstly. Then, the combustion chemical reaction mechanism is reviewed based on chemiluminescence, natural-luminosity, and laser diagnostics. After, the evolution of pollutant emissions measured by different laser diagnostic methods is reviewed and the measured species including NO, soot, UHC, and CO. Finally, a summary and the future directions on HCCI and LTC used optical diagnostics are presented.
\end{abstract}

\section{Introduction}

Homogeneous charge compression ignition (HCCI), as a new combustion mode in internal combustion engines, has been widely studied in recent 20 years. At first, the HCCI means a homogeneous charge formed by port-injection or in-cylinder early-injection is autoignited as the temperature and pressure are high enough in the cylinder. Noguchi et al. [1] investigated the HCCI combustion process by a spectroscopic system in 1979 and found that the combustion chemical radicals were detected subsequently. For example, $\mathrm{CHO}, \mathrm{HO}_{2}$, and $\mathrm{O}$ radicals were first detected, followed by $\mathrm{CH}, \mathrm{C}_{2}$, and $\mathrm{H}$ radicals, and finally was the $\mathrm{OH}$ radical. This combustion process was different to the conventional gasoline engines where all radicals were observed nearly at the same time. This study work confirms that the HCCI should be initiated by the autoignition of premixed mixture due to the compression. After that, with the development of HCCI, more optical diagnostic technologies are applied to study this new combustion process. Meanwhile, researchers find that although HCCI can achieve low $\mathrm{NO}_{x}$ and soot emissions and high efficiency, the operation range is limited and the control on autoignition timing is difficult compared to conventional diesel and gasoline engines. Therefore, some new strategies, such as active stratification on temperature and charge, changes of fuel properties, and different injection strategies, are used to solve the disadvantages of HCCI. More new combustion models, such as premixed charge combustion ignition (PCCI) and diesel low temperature combustion (LTC), have been developed. In fact, all these new combustion modes are dominated by the chemical reaction kinetics, and the combustion emits low $\mathrm{NO}_{x}$ and soot emissions, but high $\mathrm{UHC}$ and $\mathrm{CO}$ emissions.

In previous HCCI and LTC review papers, such as papers by Yao et al. [2], Dec [3], Musculus et al. [4], and Komninos and Rakopoulos [5], they have introduced that how to extend the HCCI and LTC operating range and to control the autoignition timing. In this paper, we will focus on the physical and chemical reaction processes in HCCI and LTC by measurements of optical diagnostics, which will help readers to understand the combustion processes in HCCI and LTC and to use different optical techniques to study new combustion models. 

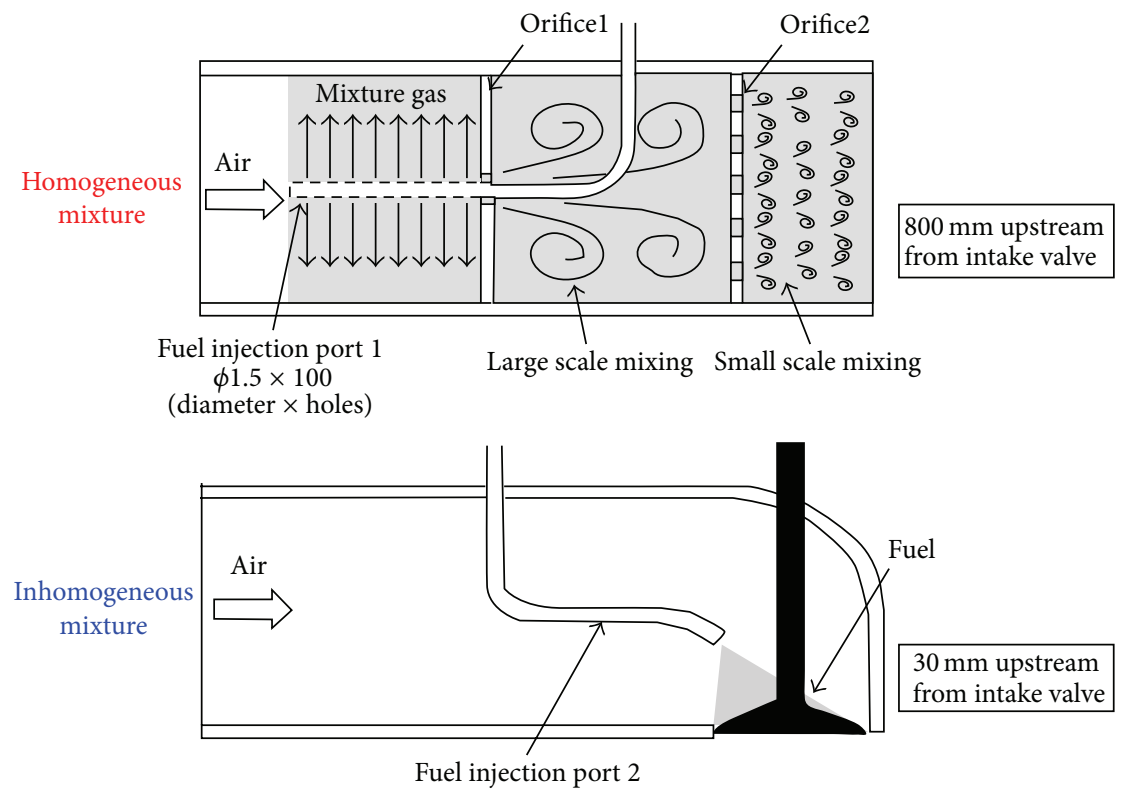

FIGURE 1: The different mixing process in the manifold [8].

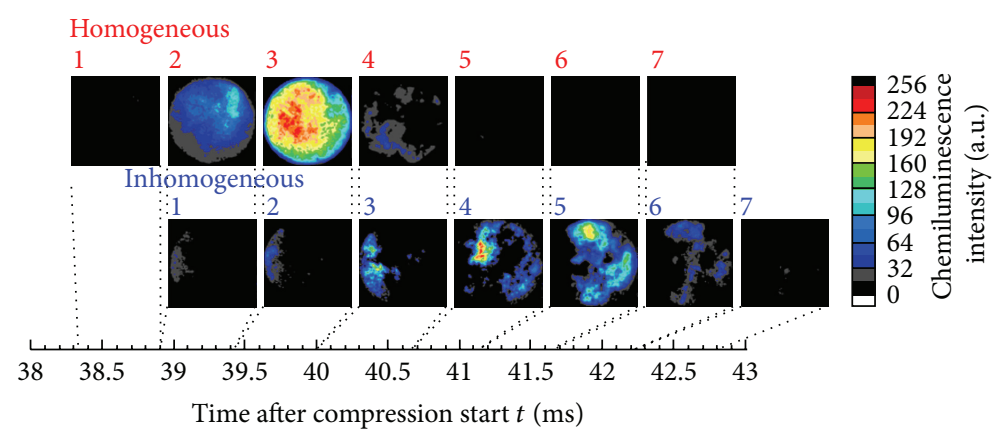

FIgURE 2: Chemiluminescence images with different mixing process [8].

\section{Optical Diagnostics for In-Cylinder Mixture Formation}

The mixture formation of fuel and air is physical process, but it has large effect on combustion chemistry subsequently. Therefore, the mixing process is reviewed firstly based on both port-injection and in-cylinder direct-injection. Finally, mixture formation combined by port and in-cylinder injection will also be reviewed.

2.1. Mixture Formation by Port Injection. Although the fuel distribution in the HCCI engine is homogeneous in macroscopically due to a quite long premixed time, the inhomogeneity in fuel distribution and temperature is lying in microscopically and thus may affect the autoignition and subsequent combustion process. Richter et al. [6] investigated the images of fuel/air mixture by using planar laser induced fluorescence (PLIF) in a HCCI engine. Two different premixing procedures were used to obtain different degrees of homogeneity of the fuel/air charge. One was a standard port injection to form the premixed charge, and the other was an additional preheated mixing tank of 20 liters to prepare a more homogenous charge. The PLIF measurement confirmed that different fuel preparation strategies affected the fuel/air homogeneity and the spatial variations of the combustion process. In the further study [7], Richter et al. found that even if the PLIF results presented a high degree of homogeneity, they were still lying in local inhomogeneous fluctuations by the measurements of Raman scattering which was caused by cycle-to-cycle variations.

Kumano et al. [8] investigated the effects of charge inhomogeneity on the HCCI combustion process. The chemiluminescence images were obtained by using a framing camera on an optical engine and dimethyl ether (DME) was used as a test fuel. The designed device was fixed into more upstream of intake manifold to form more homogeneous charge as shown in Figure 1, which was used to compare with the inhomogeneous charge. The whole combustion processes under homogeneous and inhomogeneous mixture have been shown in Figure 2. It could be seen that the combustion duration got longer at inhomogeneous mixture and thus resulted in a moderate heat release and lower maximum 
pressure rise rate. However, the homogeneous charge formed a very fast combustion process. Therefore, they concluded that the HCCI needed a local moderate combustion but not overall combustion in the cylinder.

2.2. Mixture Formation by In-Cylinder Injection. In fact, more optical diagnostics for in-cylinder mixture formation is focus on the direct injection. For extending the HCCI operating range at high load and controlling the autoignition timing, some researchers introduce stratification in the cylinder but do not form quite homogeneous charge. In order to distinguish the HCCI, some new terms, such as stratification charge compression ignition (SCCI) [9-12] and premixed charge compression ignition (PCCI) [13-18], are used. Meantime, in recent 10 years, high EGR dilution low temperature combustion (LTC) [19-26] have been studied widely in diesel engines due to the fact that it is more practical than HCCI. All in all, all of these combustion modes need direct-injection and thus the mixture preparation is more complicated than that of port-injection.

Musculus [19] investigated the in-cylinder spray and mixing processes at LTC conditions and the oxygen concentration was $12.7 \%$. The optical engine operated at low load of 4-bar indicated mean effective pressure (IMEP). The start of injection (SOI) was set to $-22^{\circ} \mathrm{CA}$ ATDC and both naturally aspirated and low boost pressure at 1.34 bars were tested. Mie scattering was used to present liquid-fuel penetration, while fuel fluorescence was used to measure the vapor jet. The results have been shown in Figure 3. It can be seen that the maximum liquid-fuel penetration was between 45 and $50 \mathrm{~mm}$ for the naturally aspirated condition and 40 and $45 \mathrm{~mm}$ for the low-boost condition. However, the typical liquid-fuel penetration was about $25 \mathrm{~mm}$ at conventional diesel conditions $[27,28]$. In this work, the early-injection conditions resulted in lower ambient gas density and temperature than that of near top dead center (TDC) injection in the conventional diesel combustion. The longer penetration made the fuel impinge on the piston bowl and resulted in wetting of the piston.

Kashdan et al. [29] investigated the in-cylinder mixture distribution in an optically accessible direct-injection HCCI engine. A high-pressure common-rail injection system supplied 1100-bar injection pressure. The nozzle has 6 holes nozzle with a narrow angle (less than $70^{\circ}$ ). Planar laser induced exciplex fluorescence (PLIEF) imaging was used in this study, which allowed qualitative visualization of the mixture (liquid and vapor phase) distribution within the piston bowl through the use of exciplex forming dopants. They found that as the start of injection (SOI) was $-40^{\circ} \mathrm{CA}$ ATDC, liquid fuel typically appears $2^{\circ} \mathrm{CA}$ later. At $-33^{\circ} \mathrm{CA}$ ATDC, the liquid fuel impinges on the piston face whilst the corresponding vapor phase images acquired at this crank angle degree. At $-30^{\circ} \mathrm{CA}$ ATDC, a certain degree of fuel stratification and a fuel rich region was seen in the center of the piston bowl due to fuel impingement. Further, this stratification trend was intensified with the retard of injection timings.

Fang et al. [30-32] investigated the liquid spray evolution process by Mie scattering and the combustion processes in a high-speed direct inject (HSDI) diesel engine. Keeping the
IMEP constant, the injection timing was changed from $-40^{\circ}$ to $-80^{\circ} \mathrm{CA}$ ATDC for both conventional wide angle injector and narrow angle injector to form the homogeneous charge. At $-40^{\circ} \mathrm{CA}$ ATDC injection, the air density and temperature were higher and liquid spray tip impinged on the bowl wall and there was only a little fuel film on the bowl wall and thus the poor fire area was quite small. However, at $-80^{\circ} \mathrm{CA}$ ATDC injection, the liquid spray impinged on the piston top and some fuel collided with the cylinder liner and then flowed into the crankcase without combustion, which would worse fuel economy and dilute oil. Although the narrow angle injector could reduce the fuel deposited on the liner, the narrow angle injector could also lead to fuel-wall impingement on the bowl wall and subsequent pool fires. The similar wall wetting was also observed by other study works, such as Liu et al. [33] and Kiplimo et al. [34].

Steeper and de Zilwa [35] investigated two gasoline direct injection (GDI) injectors on a HCCI engine at the stratified low-load condition. One injector has 8 holes with $70^{\circ}$ spray angle and the other is a $53^{\circ}$-degree swirl injector. The Mie scattering and LIF were used to measure the spray development and fuel distributions and the results showed that probability density function (PDF) statistics of equivalence ratio distribution were similar for two injectors, but the 8hole injector produced smaller and more numerous fuel packers than that of swirl injector.

Liu et al. [36] investigated spray penetration under different ambient temperatures (700-1000 K) covering both conventional diesel combustion and LTC conditions. Results showed that the liquid penetration lengths were reduced due to the heating caused by the downstream combustion flames. Compared to higher ambient temperatures, the lower ambient temperature had smaller effects on liquid penetration length, as shown in Figure 4. Furthermore, compared to soybean biodiesel, $n$-butanol spray only had a little change on liquid penetration length, which should be due to the longer soot lift-off for n-butanol spray flames.

\subsection{Mixture Formation Combined by Port and In-Cylinder} Injection. Recently, the dual-fuel injection combined by port and in-cylinder has been studied widely to achieve high efficiency and clean combustion [37-42]. By this dual-fuel injection, the homogeneous mixture can be formed by port injection using high volatility fuels, while the in-cylinder injection is used to form different stratification in the cylinder by changing injection timings. In addition, in dualfuel injection system, two fuels with opposite autoignition characteristics, such as one high octane number and the other low octane number fuel, can form different fuel reactivity in the cylinder, which can also control autoignition and extend operating range of high efficiency and clean combustion. The optical diagnostics on mixing formation in dual fuel injection are limited and Figure 5 presents charge stratification and reactivity stratification studied in [37].

From what has been discussed, it can be concluded that the direct-injection strategy has more advantages than that of port-injection for HCCI autoignition control and operating range extending. However, as using early direct-injection strategy, it helps to form a more uniform air-fuel mixture 


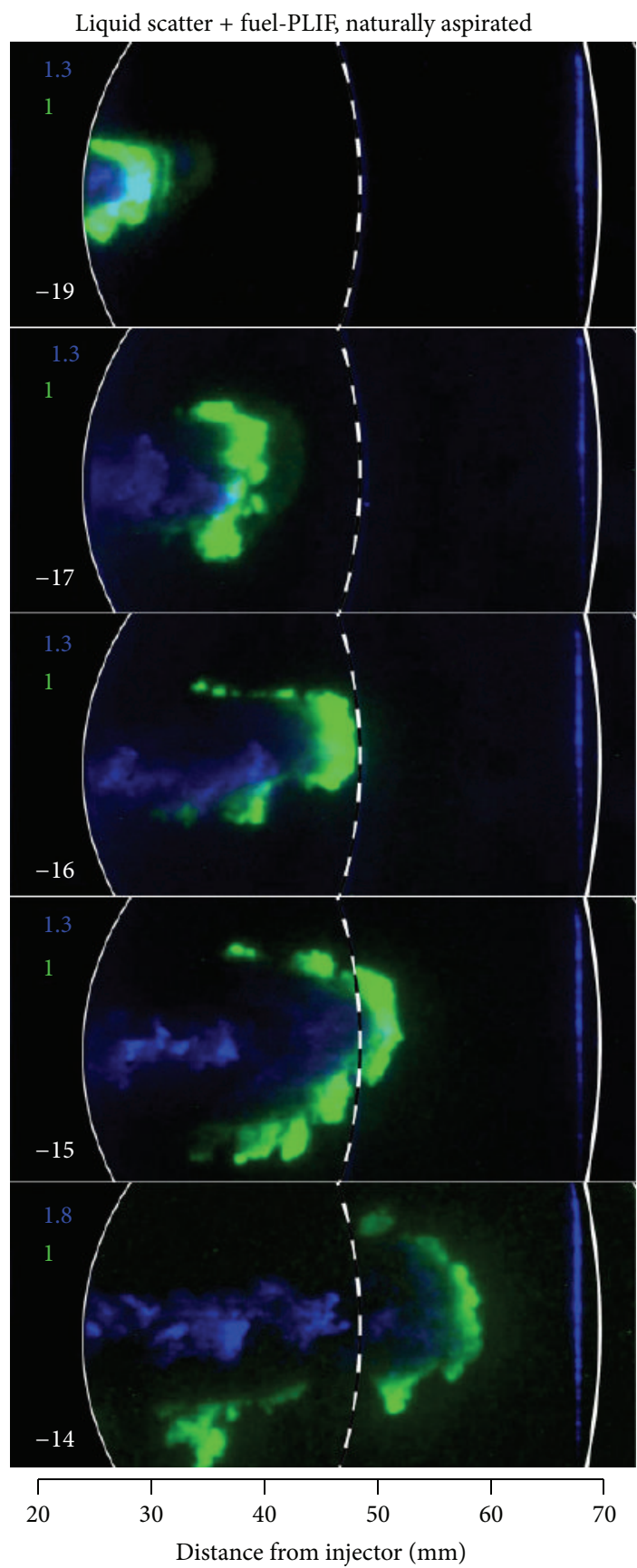

(a)

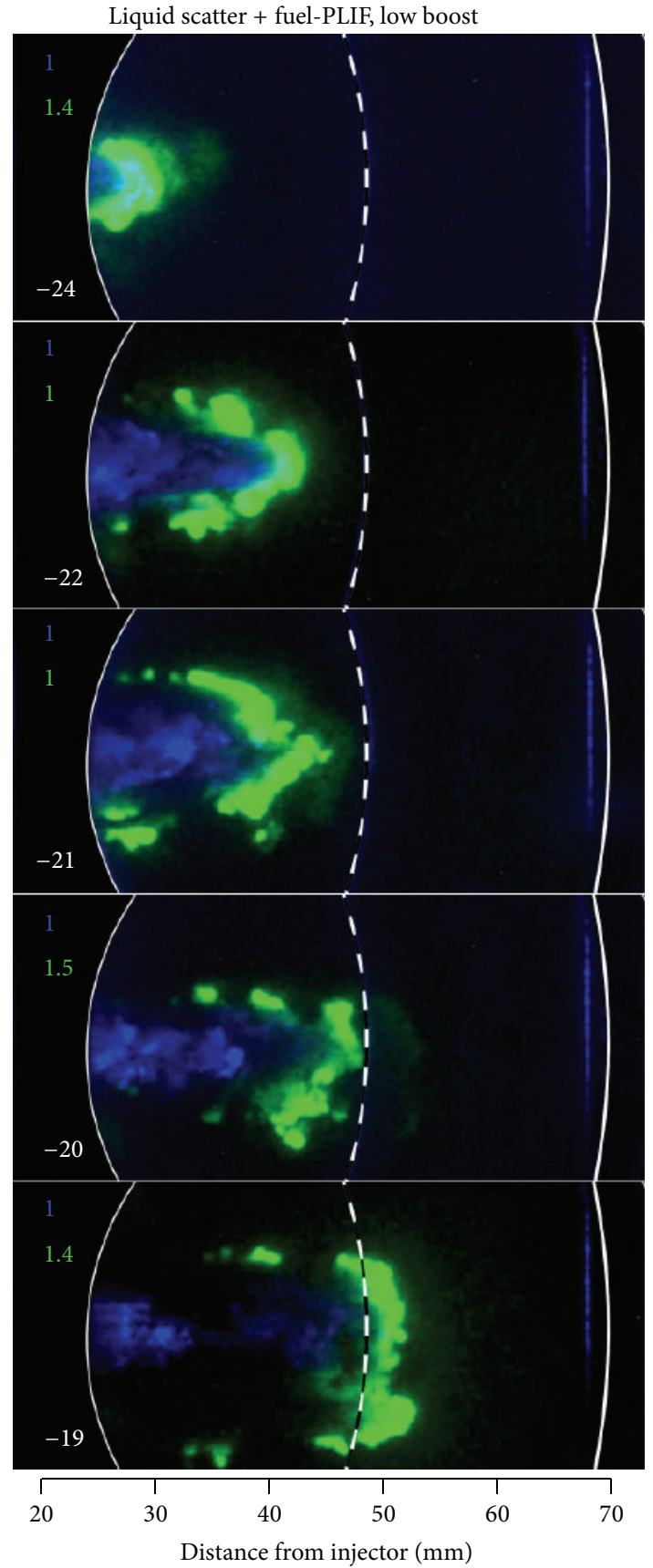

(b)

FIGURE 3: Liquid fuel (blue) and vapor fuel perimeter (green) for naturally aspirated (a) and low-boost (b) conditions (the dashed line is the edge of piston bowl-rim) [19].

before ignition but fuel can impingement on the piston head or the cylinder liner and results in wall-wetting and the dilution of oil. Some optimized methods have been carried out, such as using the narrow angle injector [30-32], 2stage or multistage injection [18,43,44], and super high injection pressures $[45,46]$ and the reader can find detailed improvement for mixing processes based on these references.

\section{Optical Diagnostics for Chemical Reaction Processes}

3.1. Chemiluminescence Imaging/Natural-Luminosity and Spectral Analysis. As stated in [47], chemiluminescence often starts from low temperature combustion due to relaxation of the excited combustion radicals to their ground 

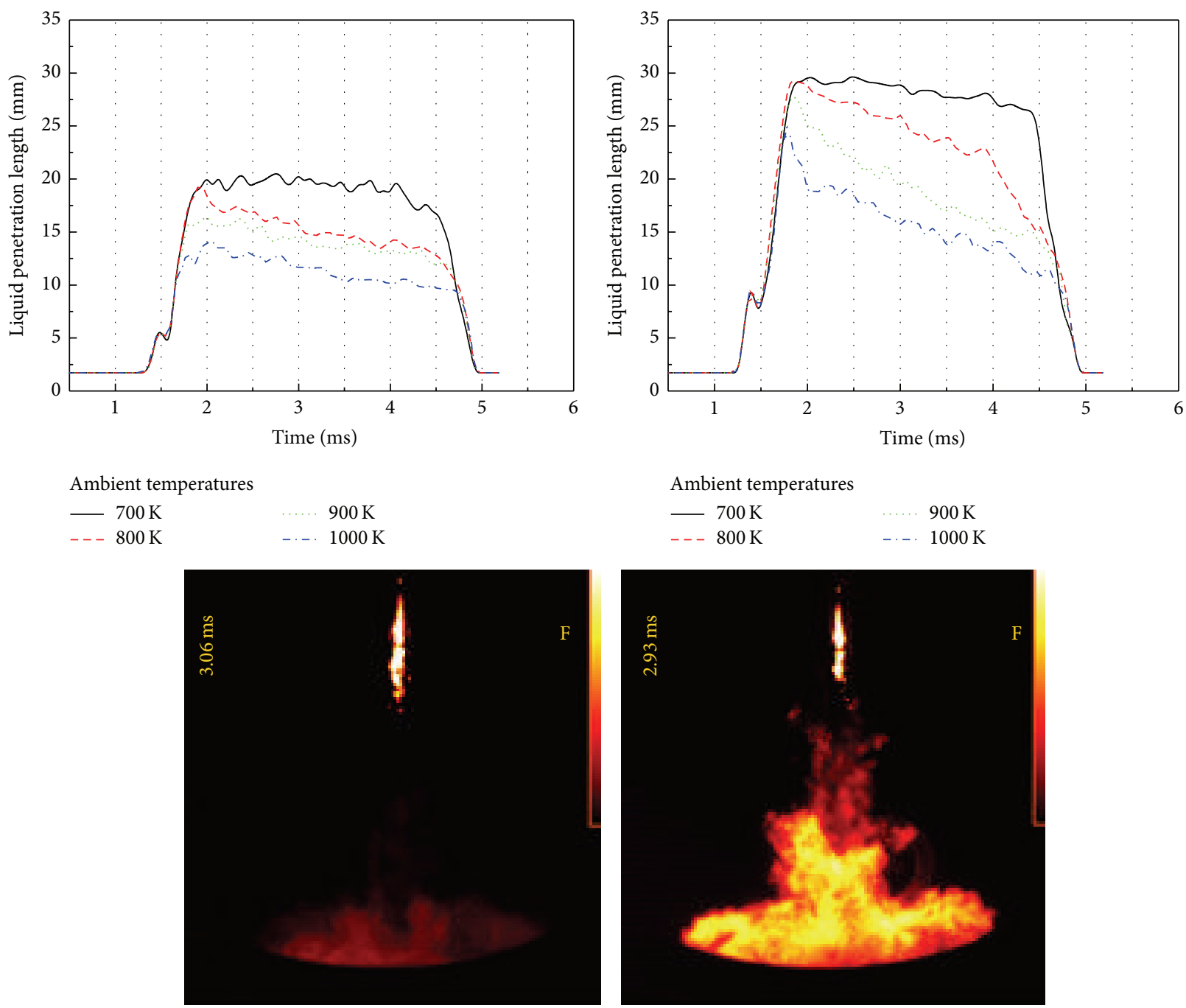

Ambient temperatures

$\begin{array}{lll}-700 \mathrm{~K} & \ldots . .900 \mathrm{~K} \\ --800 \mathrm{~K} & -.-\cdot 1000 \mathrm{~K}\end{array}$

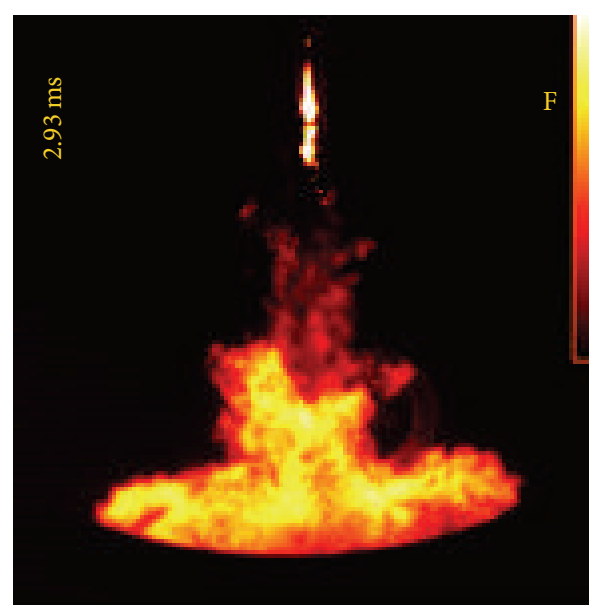

FIGURE 4: Liquid penetration lengths at different ambient temperatures for $\mathrm{n}$-butanol and soybean biodiesel [36].

states, which indicates the start of exothermic chemical reaction and heat release. Generally speaking, natural flame emission from conventional diesel combustion includes two parts: chemiluminescence and soot luminosity. For diesel combustion, chemiluminescence often comes from the visible and near ultraviolet bands due to $\mathrm{OH}, \mathrm{CH}, \mathrm{CH}_{2} \mathrm{O}$, and $\mathrm{C}_{2}$ radicals [48]. However, the chemiluminescence signal is quite weak in diesel combustion and the ICCD camera is needed to capture these nonluminous flames. It should be noted that chemiluminescence exists on the whole diesel combustion process, but it is overwhelmed by strong radiation from luminous flame after soot is generated in the flame. The soot luminosity in the GDI engine is also very strong and thus the chemiluminescence from interesting species produced in combustion processes will be disturbed. The similar problem can also be found in the spectral analysis. The spectral analysis has been used as an in-cylinder diagnostics for many years [49]. However, due to the strong black body radiation from soot particles, the signal to noise ratio is usually too low for detecting the specific species if the flame includes a large amount of soot particles.
Most researches involved with spectral analysis were applied to the conventional gasoline engines or diesel engines with low sooting fuels such as dimethyl ether (DME). But for the new combustion models, such as HCCI, PCCI, and LTC, they only emit very low soot emissions. Therefore, the chemiluminescence images and spectral analysis are more suitable to these new combustion modes. In this part, the chemiluminescence imaging and spectral analysis will be introduced in these new combustion modes. And the soot luminosity optical diagnostics will be introduced in the next section.

3.1.1. Chemiluminescence Analysis for HCCI. Hultqvist et al. [50] investigated the HCCI combustion process using chemiluminescence images and spectra fueling the blends of n-heptane and isooctane. Cool flames were found at about $-20^{\circ} \mathrm{CA}$ ATDC with a weak and homogeneous distribution in the visible area, which was called as low temperature heat release (LTHR). After cool flames, no luminosity could be captured until the main heat release started. During high temperature heat release (HTHR), the fuel/air mixture begins 

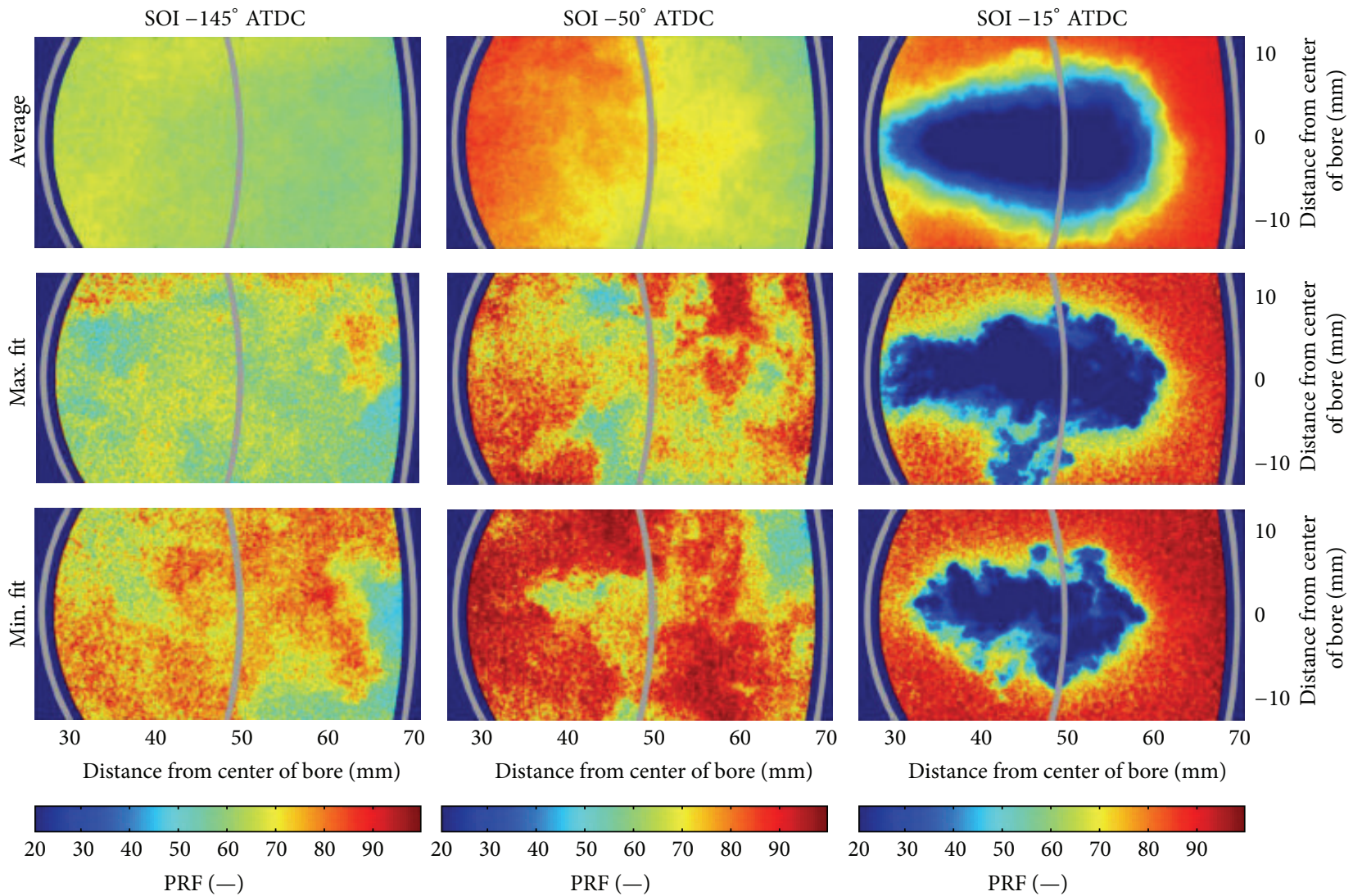

Distance from center of bore $(\mathrm{mm})$

Distance from center of bore $(\mathrm{mm})$
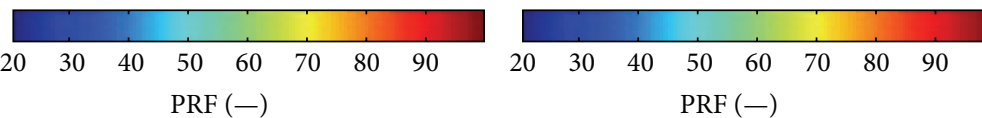

FIGURE 5: Comparison of ensemble-averaged and single shot PRF images at $-5^{\circ}$ ATDC [37].

to autoignition simultaneously at arbitrary points throughout the visible area. The peak light intensity at HTHR is one order of magnitude greater than that of LTHR. Kim et al. [51] investigated HCCI combustion with dimethyl ether in a single cylinder engine using spectra analysis. Results showed that the cool flames in LTHR was derived from HCHO according to Emeléous's bands while the $\mathrm{CO}-\mathrm{O}$ recombination spectra was the main emission during HTHR and a strong correlation was obtained between high temperature heat release and the CO-O recombination spectra.

Augusta et al. [52] investigate the effects of different engine operating parameters on the chemiluminescence spectra in a HCCI engine and the changes of operating parameters including the intake temperatures, fuel supply methods, and engine loads. Results found that the changes of engine operating parameters led to different autoignition timings but these operating parameters did not affect the reaction pathways of HCCI combustion once the combustion started. Several distinct spectra peaks emitted by $\mathrm{CHO}$, $\mathrm{HCHO}, \mathrm{CH}$, and $\mathrm{OH}$ could be observed and all these spectra were superimposed on the $\mathrm{CO}-\mathrm{O}$ continuum. The similar results have also been obtained in the study works of Liu et al. [53] and Murase et al. [54].

Mancaruso and Vaglieco [55] investigated the autoignition and combustion processes of HCCI in a diesel engine with high-pressure common-rail injection system. By using common-rail injection system, the total fuel mass per cycle was split into five injections. The chemiluminescence images and spectra showed that the $\mathrm{HCO}$ and $\mathrm{OH}$ were homogenously distributed in the visible area. Since a large amount of $\mathrm{OH}$ radicals were captured in the visible area, it suggested that $\mathrm{OH}$ radicals should be contributed to the soot reduction in the cylinder. The $\mathrm{OH}$ radicle was a suitable tool to identify the start of HTHR and phase the rate of heat release.

All in all, the HCCI combustion process can be described as following. At LTHR, a homogeneous weak light can be observed throughout the chamber, which is caused by the HCHO chemiluminescence. At HTHR, more strong luminosity derived mainly from $\mathrm{CO}-\mathrm{O}$ continuum and $\mathrm{OH}$ is a mark of the start of high temperature reaction. Between LTHR and HTHR, no luminosity can be captured.

3.1.2. Chemiluminescence/Natural-Luminosity Analysis of Stratified HCCI. Dec et al. [56, 57] investigated the HCCI chemiluminescence imaging on a single-cylinder optical engine by a high-speed intensified camera. Isooctane, as a surrogate of gasoline, was used as the test fuel and the start of injection was set to $-320^{\circ} \mathrm{CA}$ ATDC. High-speed chemiluminescence images show that the HCCI combustion has a progressive process from the hot region to cold region even as the fuel and air are fully premixed before intake occurs, as shown in Figure 6. This result demonstrated that the HCCI combustion was not homogeneous and they thought that the inhomogeneities should be derived 

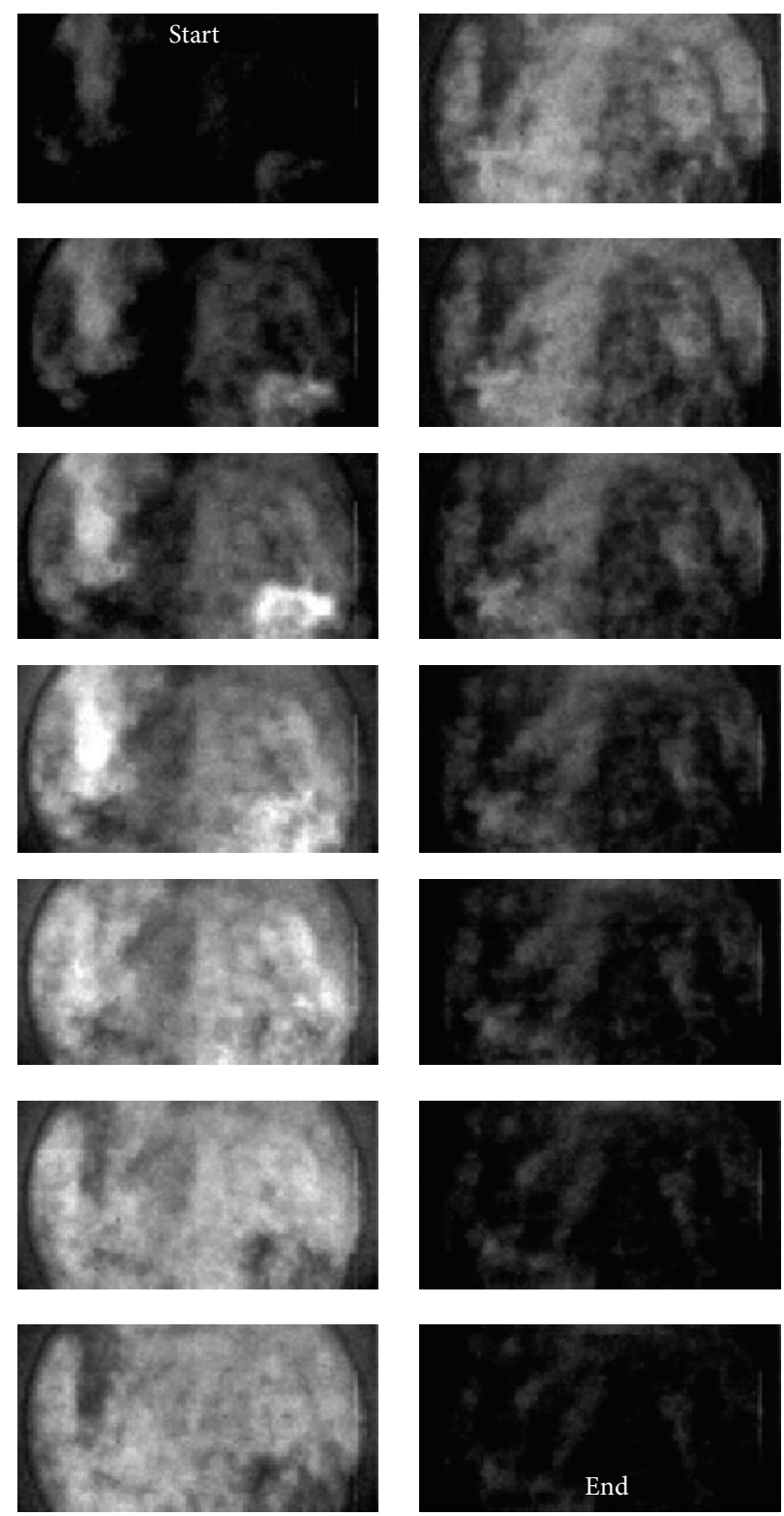

FIGURE 6: High-speed movie sequence of HCCI (the interval between frames as displayed is $100 \mu \mathrm{s}(0.71 \mathrm{CAD})$, and exposure time is $49 \mu \mathrm{s}$ per frame) [56].

primarily from naturally thermal stratification caused by heat transfer during compression and turbulent transport in the cylinder. And these inhomogeneities could slow the pressure rise rate (PRR) and thus had more advantages on the high-load extending. It should be noted that this propagation is derived from autoignition but does not take place through flame propagation because the global propagation speed is much higher than some very fast turbulent hydrocarbon flames $[58,59]$. Furthermore, the similar HCCI combustion processes have also been found by Hultqvist et al. [60]. Therefore, the HCCI combustion process also includes the temperature or thermal stratification caused by the heat transfer in the cylinder. If we can strengthen the charge or thermal stratification through some active methods, such as different injection strategies, internal or external EGR, the geometry of combustion chamber, and the modulated intake temperatures, the HCCI operating range will be extended further and the combustion phasing should be controlled.

Vressner et al. [61] investigated the effects of turbulence on HCCI combustion and the turbulence was formed by two different combustion chamber geometries: one disc shaped and the other a square bowl in piston. The chemiluminescence images demonstrated that the combustion began in the square bowl and propagated to the squish volume. The combustion process was more stratified in the square bowl geometry because of temperature inhomogeneities. The piston with a square bowl can form stronger turbulence than that of disc shaped piston, and then the variation of turbulence intensity will form the temperature stratification in the cylinder. Therefore, 2 -stage combustion including in 

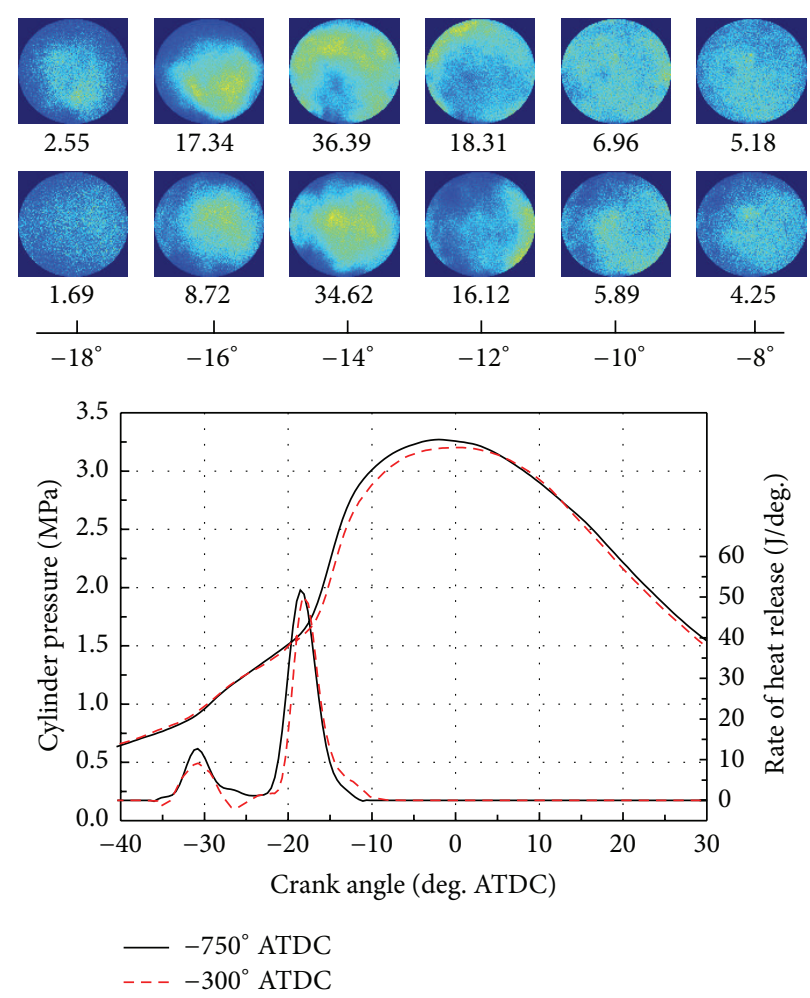

FIGURE 7: Chemiluminescence images under different intake and coolant temperatures with the same $50 \%$ burn point and SOI $=-300^{\circ} \mathrm{CA}$ ATDC; $T_{\text {in }}=95^{\circ} \mathrm{C}, T_{c}=85^{\circ} \mathrm{C}$ (first) and $T_{\text {in }}=125^{\circ} \mathrm{C}, T_{c}=55^{\circ} \mathrm{C}$ (last). The number below each image is the light intensity [62].

and out the square bowl was observed and led to a lower PRR compared to the disc shaped combustion chamber where the turbulence and temperature were more homogeneous and thus the autoignition occurred simultaneously in the chamber.

Liu et al. $[62,63]$ formed different charge and temperature stratification on the HCCI combustion by modulating injection timings, intake and coolant temperatures, and combustion chamber geometries. Figure 7 showed the chemiluminescence images with different temperature stratifications. The higher intake temperature of $125^{\circ} \mathrm{C}$ and lower coolant temperature of $55^{\circ} \mathrm{C}$ formed larger temperature stratification in the visible area and thus the combustion presented more inhomogeneous than that of intake temperature of $95^{\circ} \mathrm{C}$ and coolant temperature of $85^{\circ} \mathrm{C}$ where the in-cylinder had lower temperature stratification. The larger temperature stratification resulted in lower heat release rate and had the potential to extend the operating range to higher loads. Figure 8 presented the HCCI combustion process with different combustion chamber geometries. Various squish lip configurations as shown in Figure 9 generated different turbulence motion in the chamber and therefore the autoignition location for $\mathrm{V}$-type and $\mathrm{H}$-type geometries was more dispersive and near to the chamber wall, while the autoignition of A-type geometry always started in the center of the chamber due to the fact that high turbulence intensity in the bowl resulted in larger heat loss through the chamber wall. Therefore, the A-type geometry induced higher turbulent kinetic energy and led to larger temperature inhomogeneities, which had more advantages on reducing PRR and heat release rates. This proves that the change of piston geometry can induce different turbulence or temperature stratification, which will affect the HCCI combustion processes although it is generally thought that HCCI is controlled by chemical kinetics.

Aleiferis et al. [64] generated charge and thermal stratification under HCCI conditions by different injection timings and by both inlet air heating and residual gas trapping (internal EGR). Combustion images showed that the larger temperature inhomogeneities in the cylinder would lead to slower autoignition front moving speed. These temperature inhomogeneities were derived from the difference in injection timings without EGR conditions or from the mixing between the fresh fuel/air and the trapped residual gases in cases with IEGR.

Berntsson and Denbratt [65] investigated the effect of charge stratification on combustion and emissions under HCCI operating conditions. Port injection was used to create a homogeneous charge in the cylinder, while a GDI injector was used to form charge stratification. They compared the early autoignition process on both homogeneous and stratified conditions. From autoignition appearing to reactions taking place throughout the combustion chamber, the HCCI with homogeneous conditions would spend $4^{\circ} \mathrm{CA}$, while the stratified condition spent $8^{\circ} \mathrm{CA}$. Furthermore, the combustion images showed that the combustion duration was enlarged because the local variation of equivalence ratio can moderate the rate of heat release and thus can further extend HCCI operating range. 


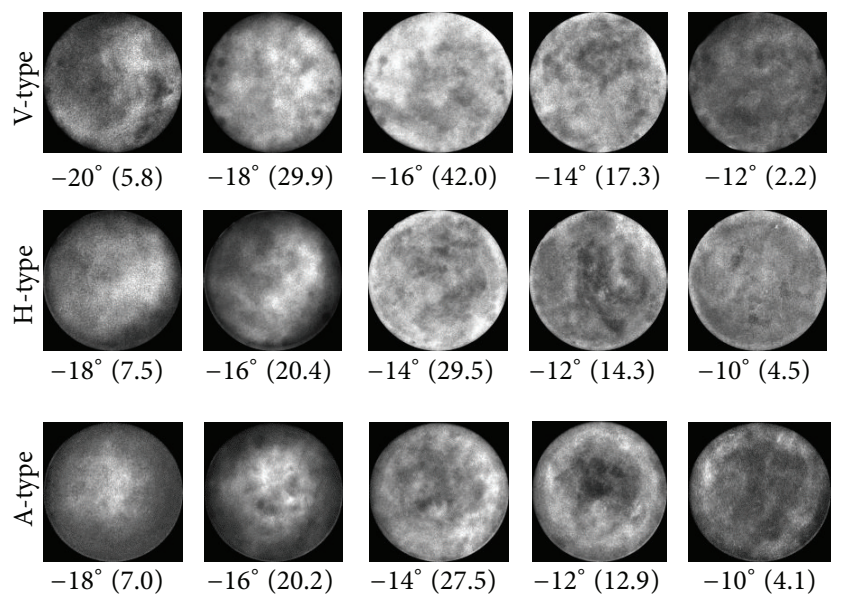

(a)

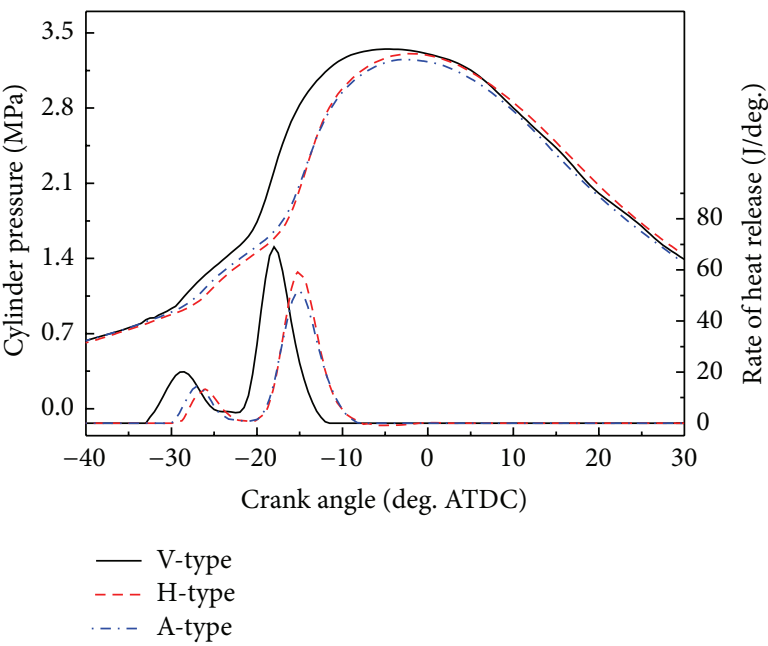

(b)

FIGURE 8: Chemiluminescence images, cylinder pressure, and rate of heat release with various piston bowl geometries at $T_{\text {in }}=95^{\circ} \mathrm{C}, T_{c}=$ $85^{\circ} \mathrm{C}$. The number below each image is the crank angle and light intensity [63].

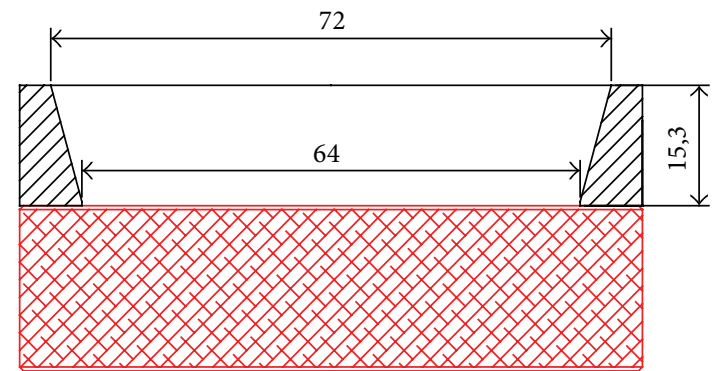

(a) V-type combustion chamber

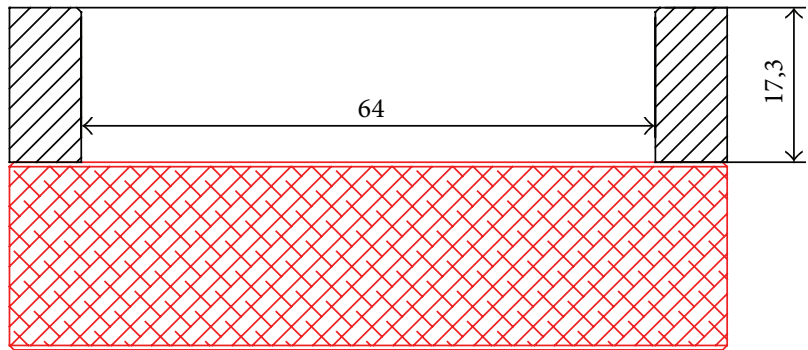

(b) H-type combustion chamber

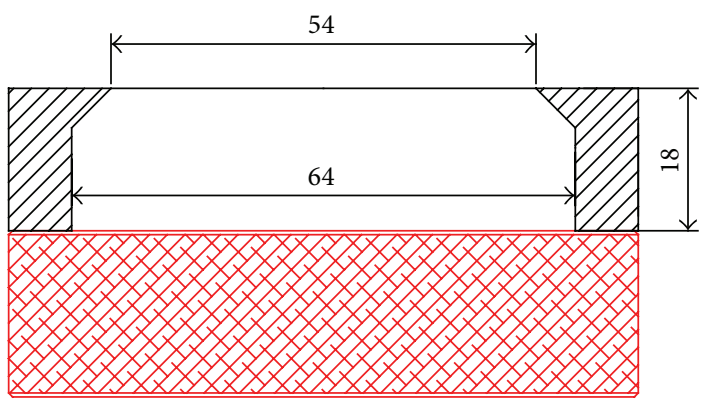

(c) A-type combustion chamber

FIGURE 9: Various piston bowl geometries with the same compression ratio, squish distance, and visible area [63].

Kook and Bae [66] investigated the premixed charged compression ignition (PCCI) combustion by two-stage injection strategy in a diesel engine. The first injection $\left(10 \mathrm{~mm}^{3}\right)$ was set to $-200^{\circ} \mathrm{CA}$ ATDC to generate homogeneous and complete mixture between diesel and air. The second injection $\left(1.5 \mathrm{~mm}^{3}\right)$ was set to $-15^{\circ} \mathrm{CA}$ ATDC as an ignition promoter and to control the autoignition process. The injection pressure was controlled at $120 \mathrm{MPa}$. Meanwhile, the conventional diesel combustion was also tested in comparison with PCCI, of which total fuel $\left(11.5 \mathrm{~mm}^{3}\right)$ was injected into the cylinder at $-15^{\circ} \mathrm{CA}$ ATDC directly. The luminous flame could be observed due to the thermal radiation from soot as shown in Figure 10. However, for the PCCI, the luminous flames were quite weak and the distribution was also quite limited and only located at heterogeneous combustion regions of the second injection. Finally, the authors concluded that the first injection timing needed to be advanced earlier than $-100^{\circ} \mathrm{CA}$ ATDC for the homogeneous and nonluminous flames (Figure 11).

Based on above reviews on charge or thermal stratification through some active methods, it can be found that the stratification can reduce maximum heat release rates and 

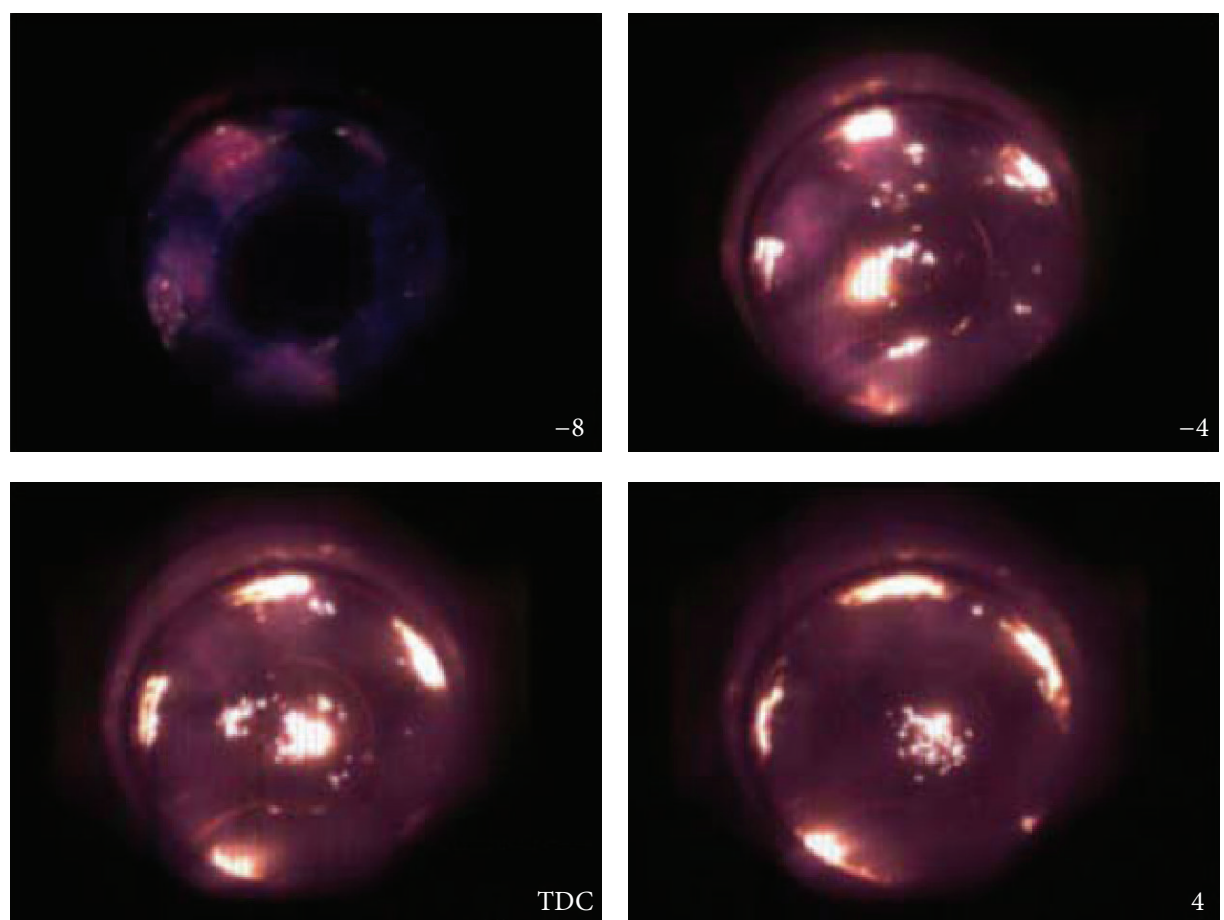

FIGURE 10: Direct-imaging of luminous DI-diesel combustion; single injection, injection timing $=-15^{\circ} \mathrm{CA}$ ATDC, injection quantity $=$ $11.5 \mathrm{~mm}^{3}$, injection pressure $=120 \mathrm{MPa}$, and injection angle $=150^{\circ}[66]$.
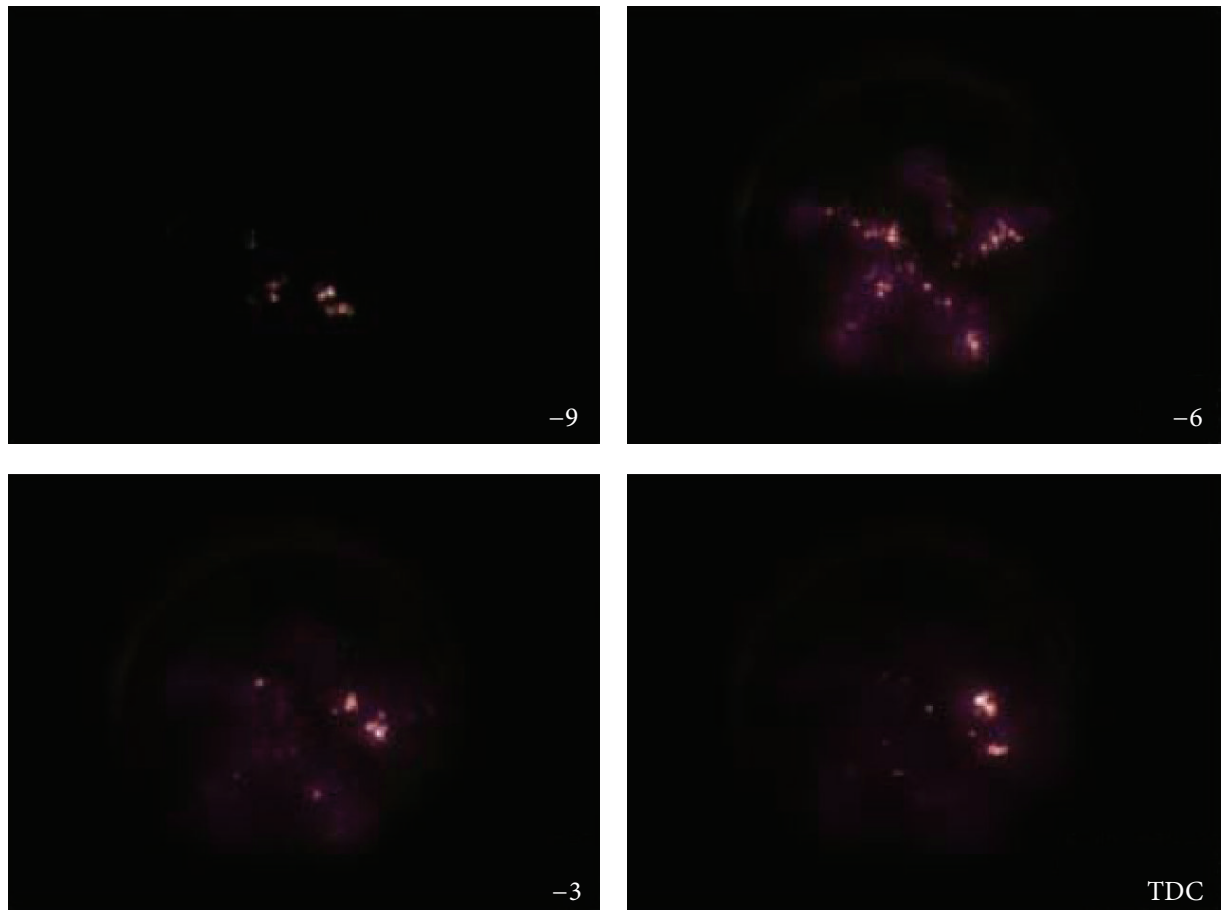

FIGURE 11: Direct imaging of PCCI combustion with two-stage injection strategy; main injection timing $=-200^{\circ} \mathrm{CA}$ ATDC, main injection quantity $=10 \mathrm{~mm}^{3}$, second injection quantity $=1.5 \mathrm{~mm}^{3}$, injection pressure $=120 \mathrm{MPa}$, and injection angle $=150^{\circ}$ [66]. 


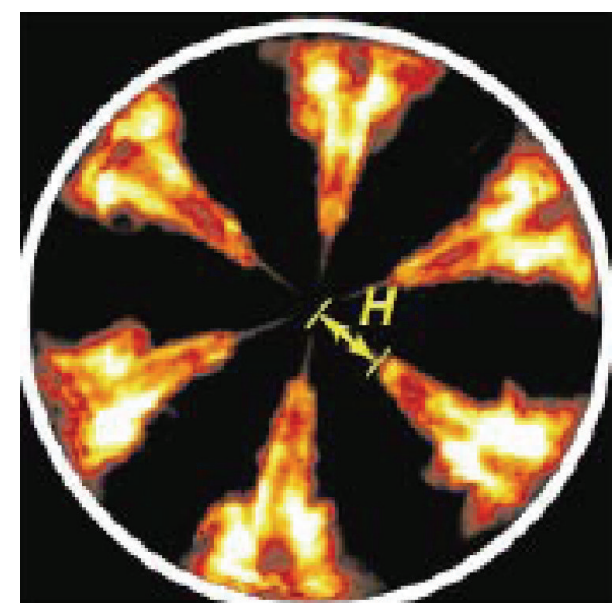

$21 \% \mathrm{O}_{2}$

$\phi_{\Omega}(H)=2.7$

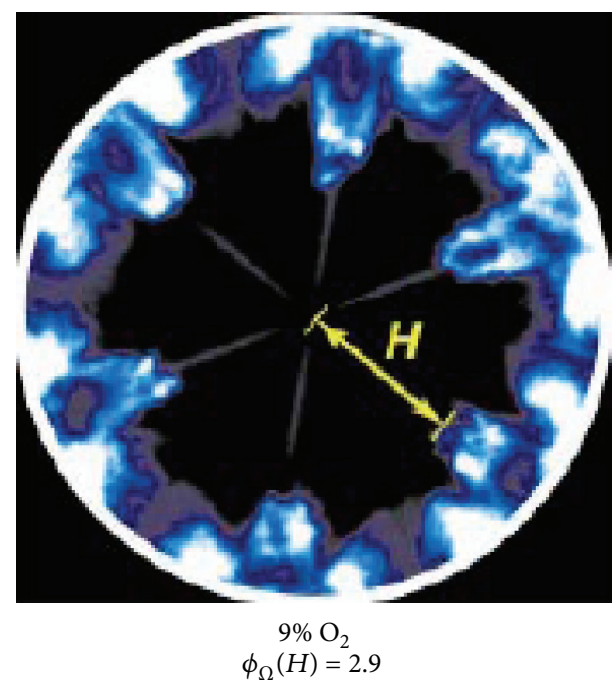

FIGURE 12: The imaging of conventional diesel and LTC [67].

pressure rise rates and thus may extend HCCI operating range. The combination between port-injection and direct injection or two-stage direct-injection in the cylinder is effective technological measures to achieve charge stratification. However, for temperature or thermal stratification, the most direct measures are changing the intake and coolant temperatures but this method is very hard to achieve in a real engine. Accordingly, the internal EGR is a more reliable method to form temperature inhomogeneity in the cylinder; however the EGR will affect the HCCI combustion by chemical action, dilution, and temperatures. Therefore, it is very hard to clarify that the temperature stratification caused by IEGR must be a very main reason on affecting HCCI combustion. In addition, a specific piston geometry will also form different turbulence intensity and thus generate the temperature inhomogeneity. Anyway, the charge and thermal stratification are effective methods to control the HCCI combustion.

3.1.3. Chemiluminescence/Natural-Luminosity Analysis of LTC. Since the diesel fuel has low volatility, the portinjection is not a practical way without significant change of intake system, such as increasing intake temperature. An early in-cylinder injection strategy, to some extent, can result in a quite homogeneous charge before ignition. However, due to lower charge density, in-cylinder pressure, and temperature, the liquid fuel impingement on the liner wall or piston wall is unavoidable, which leads to high HC and $\mathrm{CO}$ emissions and oil dilution. In recent ten years, high EGR dilution low-temperature combustion (LTC) has gained tremendous attention [67-75]. For LTC, the start of injection is near to top dead center; therefore the injection timing can control the autoignition timing to some extent. Furthermore, the later injection timing will not result in fuel impinge into piston head or cylinder liner. However, the late injection leads to the uncompleted mixing between diesel fuel and air, and thus there is a locally rich region in the mixture which is similar to diesel conventional combustion. But the soot formation can still be suppressed due to the quite low combustion temperature caused by large amounts of EGR which can avoid the soot formation region. Akihama et al. [20] firstly found that high EGR dilution can suppress soot formation on an optical diesel engine in 2001. The soot luminosity was increased firstly with the increase of EGR rates, but with higher EGR rates, soot luminosity was decreased and no luminosity was observed under quite high EGR dilution. Simultaneously, $\mathrm{NO}_{x}$ emissions can also be near to zero due to high EGR dilution and subsequent low combustion temperature. In addition, the injection characteristic (including injection pressure, timing, and multiple injections) influences the temperature during the ignition delay period, the peak flame temperature reached, and the premixing improvement. Finally, in order to keep the power density and the combustion efficiency of the engine at high EGR rates, high boost levels are required. Therefore, the control and optimize of EGR rate, injection characteristic, and high boost are the keystone of the LTC. Compared to HCCI strategy, LTC has more benefits such as high efficiency over broad load range, simple control of ignition timing, reduced pressure-rise rates, high-load capability, and so forth, besides low emissions of $\mathrm{NO}_{x}$ and soot. This is the reason why LTC is widely studied in recent years.

Upatnieks et al. [67, 71, 72] measured lame lift-off lengths using in-cylinder images of natural luminosity. Results showed that soot incandescence could not be observed even for local fuel-rich mixture, while the similar stoichiometric combustion must lead to soot incandescence without EGR dilution, as shown in Figure 12. Meanwhile, a blue flame could be seen for LTC condition, which was because of the too low flame temperature. Furthermore, the flame lift-off at LTC condition was larger than that of conventional diesel combustion. After that, Musculus et al. also investigated the LTC by different laser diagnostics and proposed the LTC combustion concept in the review paper [4].

Liu et al. $[68,73,74]$ investigated the natural luminosity under both conventional diesel combustion and low temperature combustion by using different fuels such as 
$21 \% \mathrm{O}_{2}$ concentration

Natural flame luminosity (left, $f / 32$ )

Soot distribution (right, $f / 4.5$ )
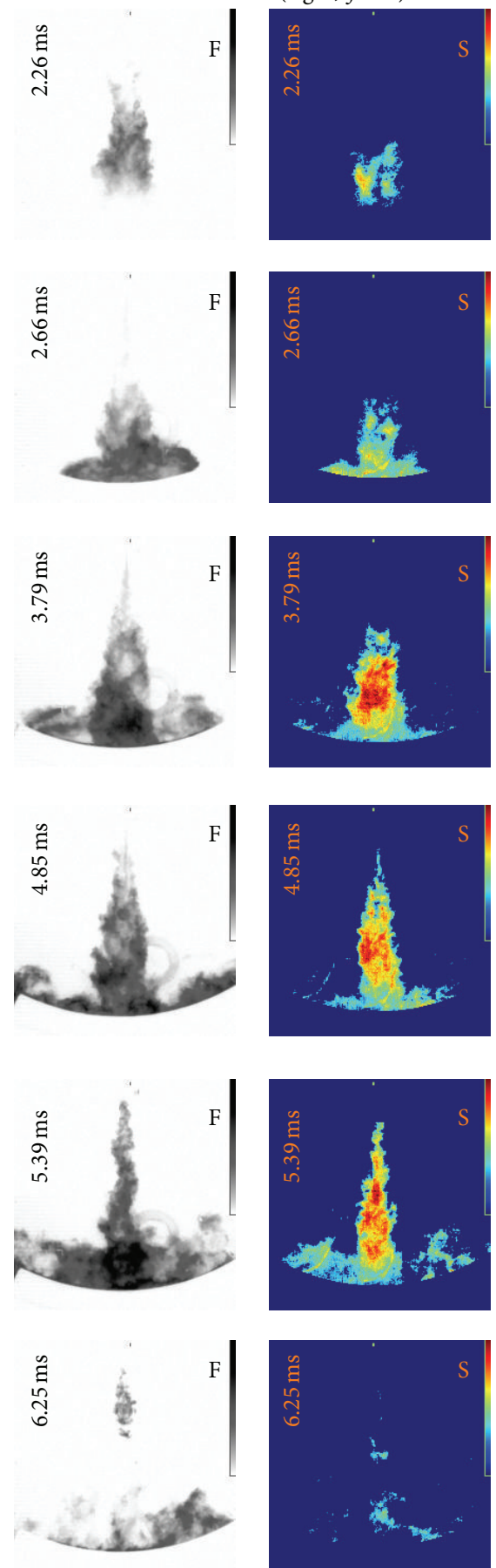

$16 \% \mathrm{O}_{2}$ concentration

Natural flame luminosity (left, $f / 32$ )

Soot distribution (right, $f / 4.5$ )
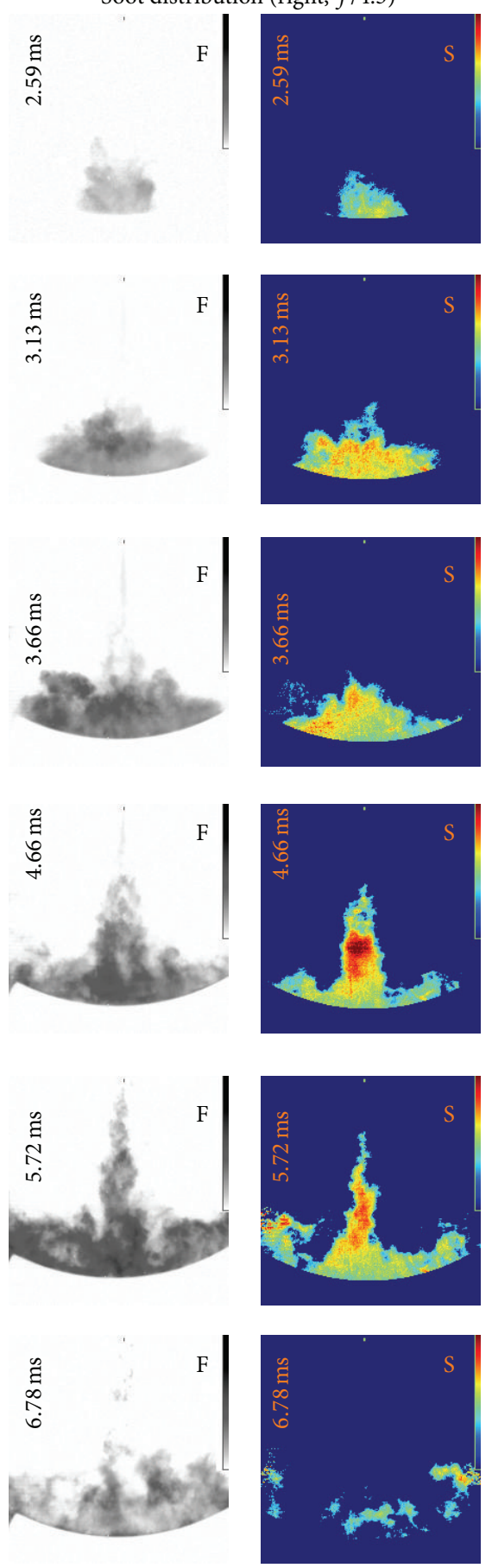
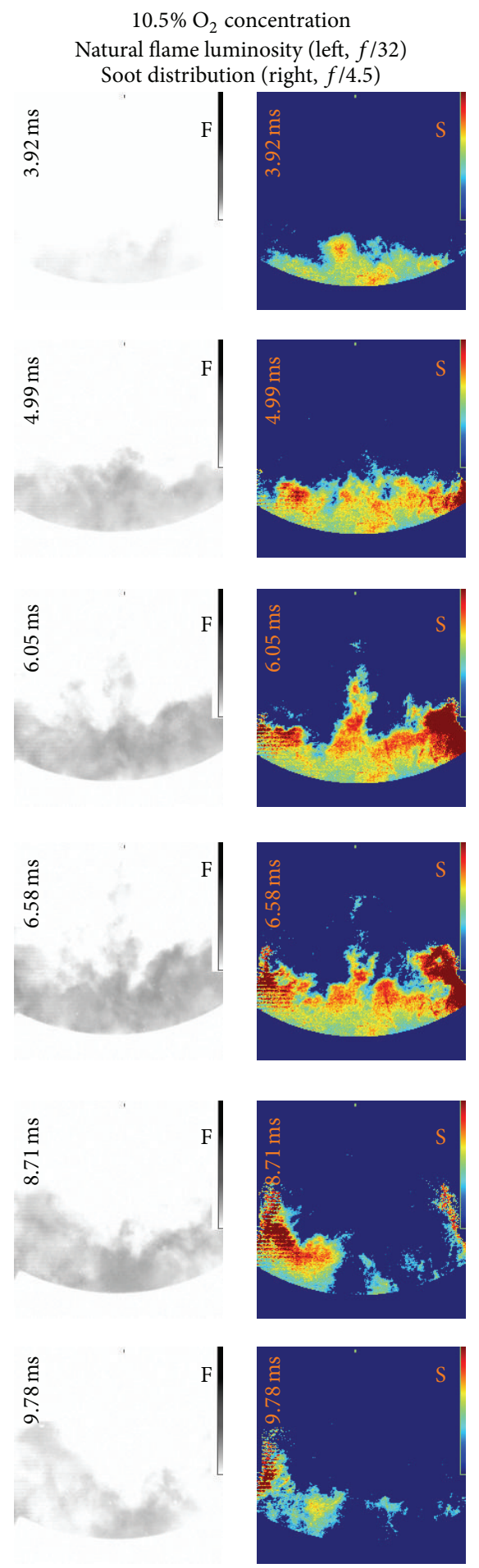

FIgURE 13: Natural flame luminosity and soot distribution for soybean biodiesel at $1000 \mathrm{~K}$ ambient temperature [68].

diesel, soybean biodiesel, n-butanol, ethanol, and the blended fuels. They found that natural flame luminosities were reduced with the decrease of ambient oxygen concentrations and ambient temperatures. Furthermore, the flame distribution or flame area was increased obviously at low oxygen concentration of $10.5 \%$ and much flame could be seen near chamber wall regions. However, the difference between high and low ambient temperatures is that even if the natural luminosity was decreased with the decline of oxygen concentrations at $1000 \mathrm{~K}$ ambient temperature, soot emissions were increased as shown in Figure 13. But, the natural luminosities and soot emissions were reduced simultaneously at $800 \mathrm{~K}$ ambient temperature as shown in Figure 14. Further analysis conducted by Bi et al. [75] found 


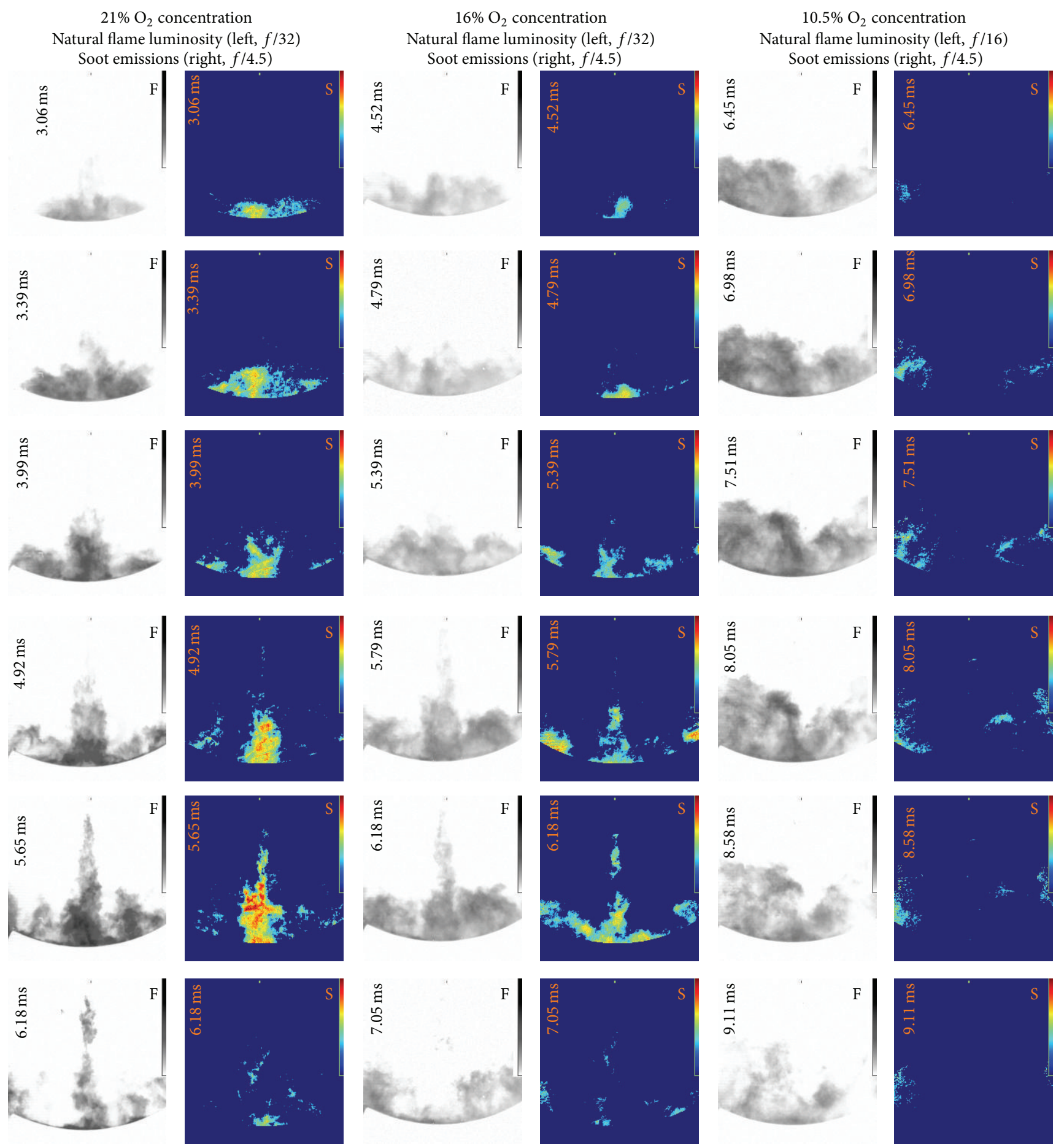

FIGURE 14: Natural flame luminosity and soot distribution for soybean biodiesel at $800 \mathrm{~K}$ ambient temperature [68].

that the changes of oxygen concentrations altered the soot formation and oxidation rates and thus resulted in different soot emissions.

Based on above reviews on natural luminosity of LTC, it can be found that the combustion flame with larger distribution was more near to cylinder wall, which means that the flame lift-off are larger than that of conventional diesel combustion. With the decrease of oxygen concentrations or with the increase of EGR rates, the natural luminosity reduced monotonously, but the soot emissions increase firstly and then decrease after achieving the peak value.

3.2. Laser Diagnostic Imaging on Chemical Reaction Processes of HCCI and LTC. Above reviews are aiming for the methods 

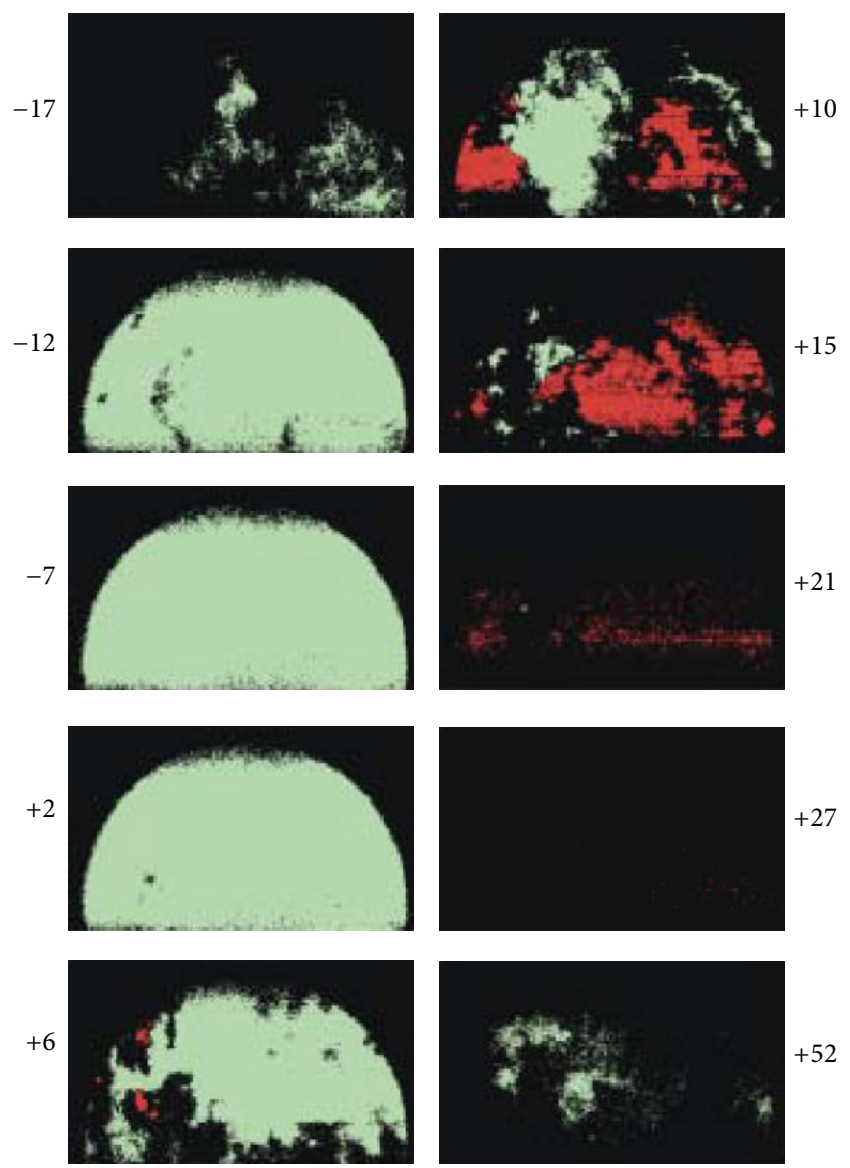

FIGURE 15: Single-shot images from onset of LTR combustion until the end of the main combustion. Formaldehyde is shown in green and $\mathrm{OH}$ is shown in red [76].

of chemiluminescence or natural luminosity. Even if the direct images are easy to measure, some combustion intermediate species cannot be measured effectively. By the laser diagnostics, the specific species can be captured by adjusting the laser wavelength. Therefore, the laser diagnostics on HCCI and LTC combustion species will be reviewed in this section.

Collin et al. [76] simultaneously measured $\mathrm{OH}$ and formaldehyde LIF on an HCCI engine using two laser sources at wavelength of 283 and $355 \mathrm{~nm}$ and two ICCD cameras were used to collect LIF signals. The blend of isooctane and n-heptane was used as tested fuel and was injected by intake port and the compression ratio of the HCCI engine was set to 12 . The width of the laser sheet was $40 \mathrm{~mm}$, which is nearly a half of the cylinder bore. Results showed that formaldehyde could be captured at the start of the low temperature reactions as shown in Figures 15 and 16. With the progress of the combustion reaction, more formaldehyde was detected in the cylinder and formaldehyde filled the entire visible area after the low temperature reactions ended. At the start of the high temperature reactions, some holes in homogeneous formaldehyde signals could be captured, which demonstrated that formaldehyde was consumed with the progress of combustion processes. At about $6^{\circ} \mathrm{CA}$ ATDC,

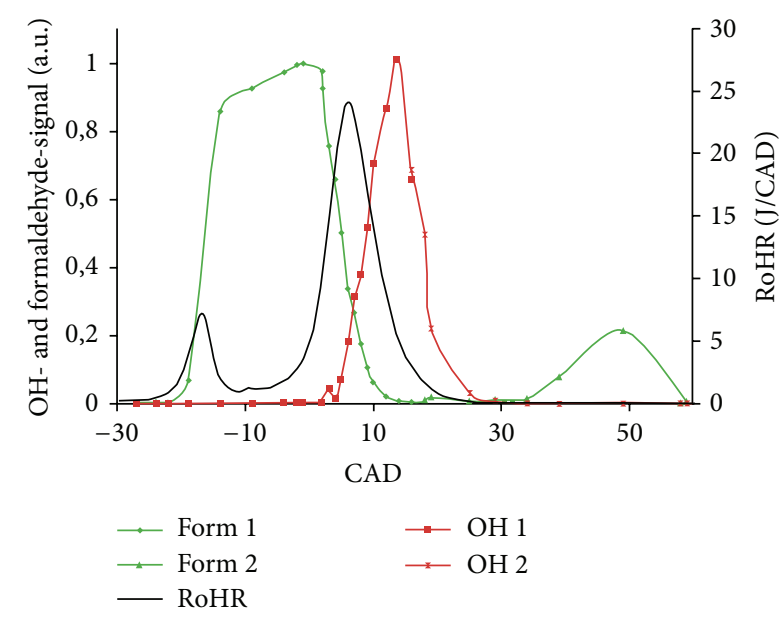

Figure 16: Average rate of heat-release and average $\mathrm{OH}$ - and HCHO-signals [76].

OH-LIF was captured firstly, and the OH-LIF could only be observed in regions where formaldehyde was absent. Under a relatively long period about 9-crank-angle degree, LIF signals of $\mathrm{OH}$ and formaldehyde were captured simultaneously but never in same regions for these two intermediate species. The OH-LIF intensity was lagging the rate of heat release (RoHR) by about 8 crank-angle degree, and the maximum $\mathrm{OH}$ intensity was captured as the most of fuel was consumed at about $15^{\circ} \mathrm{CA}$ ATDC and thus close to in-cylinder peak temperature. Therefore, the autoignition and combustion processes of HCCI can be detected by visualizing the distributions of formaldehyde and $\mathrm{OH}$ radicals. For formaldehyde, its formation occurs through low temperature oxidation in an early phase of the ignition process and then is consumed later in the combustion process. Therefore, formaldehyde is an indicator of the autoignition of low temperature heat release in HCCI engine. Meanwhile, it is also a marker for regions with low temperature reactions. For OH radical, it is formed in flame regions with high temperature and there is a strong relationship between maximum combustion temperatures and maximum $\mathrm{OH}$ concentrations.

Särner et al. [77] simultaneously investigated images of formaldehyde-LIF and fuel-tracer LIF in a direct-injection HCCI engine. The blend of $n$-heptane and isooctane was used as fuel and toluene was added as fluorescent tracer. LIF of fuel-tracer was excited by a Nd:YAG laser with the wavelength of $266 \mathrm{~nm}$, and the fluorescence was captured by an ICCD camera in the spectral region of $270-320 \mathrm{~nm}$. Formaldehyde-LIF was excited by the other Nd:YAG laser with the wavelength of $355 \mathrm{~nm}$, and the fluorescence was captured by the other ICCD camera in the spectral region of 395-500 $\mathrm{nm}$. An early injection timing ( $-250^{\circ} \mathrm{CA}$ ATDC) was used to form homogeneous charge and the distribution of fuel-tracer and formaldehyde-LIF were quite homogeneous before it was consumed at start of high temperature reaction as shown in Figure 17. However, for a late timing $\left(-35^{\circ} \mathrm{CA}\right.$ ATDC), it formed stratified charge and the distribution of fuel-tracer and formaldehyde-LIF were inhomogeneous 


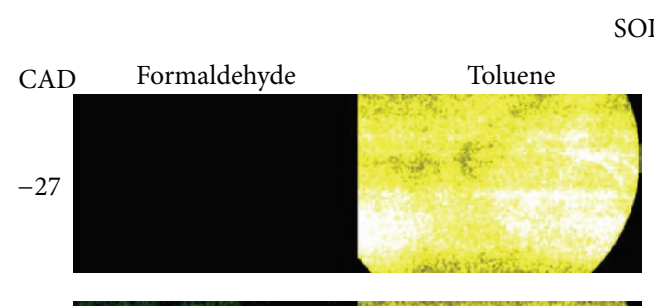

SOI $=-250$
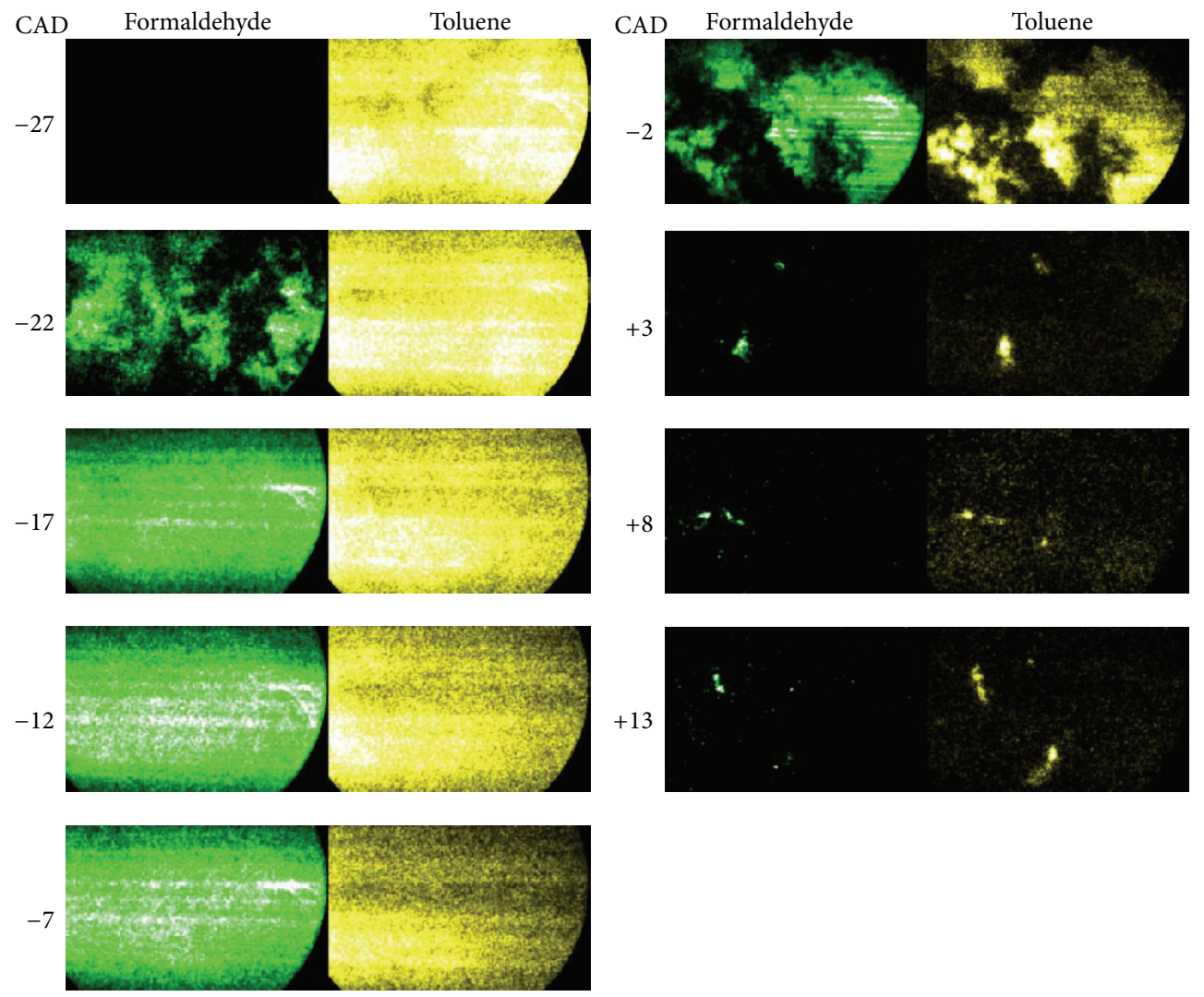

FIGURE 17: Simultaneous images of formaldehyde and toluene at start of injection of $-250^{\circ} \mathrm{CA}$ ATDC to ensure the fuel sufficient time to mix with air forming a very homogeneous mixture before ignition [77].

in the visible area as shown in Figure 18. Images from both early and late injection showed that both toluene and formaldehyde LIF signals have very similar distribution. That is to say, once fuels have higher boiling points and thus no suitable tracer can be used to measure, the formaldehyde-LIF is a good alternative method to fuel-tracer LIF.

Zhao et al. [78] investigated formaldehyde-LIF distribution on the HCCI combustion process by fueling different primary reference fuels (PRFs). They found that the formaldehyde formation was mainly affected by the charge temperature, while the fuel concentration had less effect on formaldehyde formation. Even if PRFs had different isooctane ratio, all fuels had similar formaldehyde formation timings to that of pure n-heptane, which meant that the addition of isooctane did not influent the start of low temperature reactions apparently.

Kashdan et al. [29] investigated the late-injection diesel fuel HCCI combustion process at $45 \%$ EGR dilution. They found that formaldehyde-LIF images could be captured earlier than that of chemiluminescence in early stages of the cool flame. Similar to the homogeneous conditions, formaldehyde was consumed quickly at the start of the high temperature reactions and took place by the presentence of OH-LIF subsequently. Because of the late injection resulted in some local high equivalence ratio regions, soot precursors were also captured, demonstrated by the strong PAH fluorescence.
In his further study [79], they investigated the effects of split injection and EGR rates on HCCI combustion. They found that the start of formaldehyde-LIF signals was not affected by EGR rates, but the high temperature heat release was advanced with the decrease of EGR rates and ultimately reduced the formaldehyde lifetime and consequently increased the inhomogeneous state in the cylinder. As split injection was used, formaldehyde-LIF showed locally rich distribution like the reference of 73, which demonstrated that the split injection resulted in larger charge stratification. Furthermore, the lifetime of formaldehyde-LIF was prolonged and the whole combustion duration was also prolonged.

Hildingsson et al. [80] investigated formaldehyde- and $\mathrm{OH}-\mathrm{LIF}$ on a light duty diesel engine with different injection strategies of port-injection HCCI, direct-injection HCCI, and UNIBUS. The formaldehyde formation always began at about $20-25^{\circ} \mathrm{CA}$ BTDC no matter what injection strategies were used. But the intensity of formaldehyde-LIF was very fast for port-injection HCCI compared to UNIBUS and late-injection HCCI. This should be due to the fact that port-injection can supply more homogeneous charge than that of direct-injection HCCI and UNIBUS, and thus the whole chemical reaction rates are higher. FormaldehydeLIF lifetime in the UNIBUS injection strategy was longer than that of port- or direct-HCCI because formaldehyde was formed from the dual injections of the fuel. 
SOI $=-35$
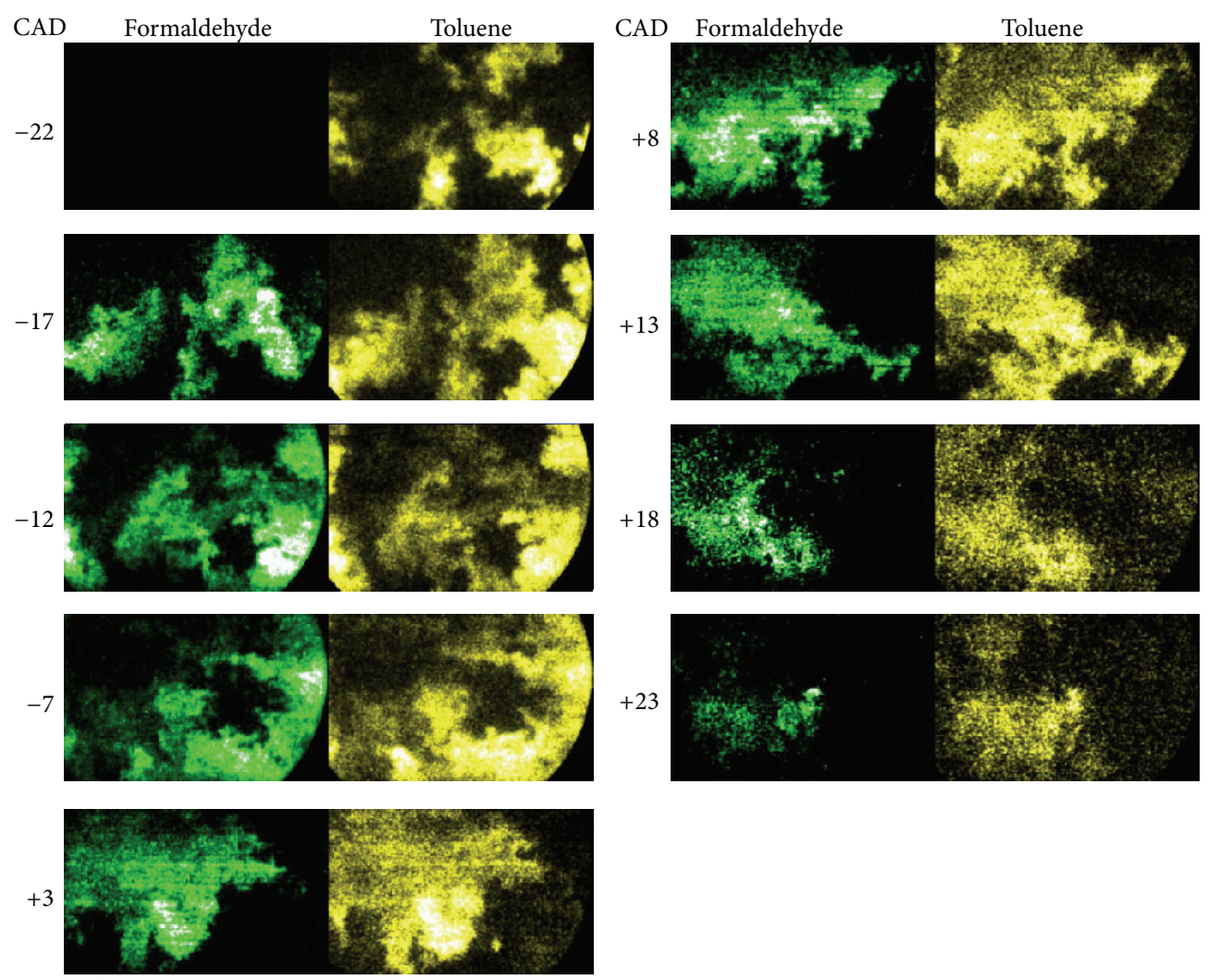

FIGURE 18: Simultaneous images of formaldehyde and toluene at start of injection of $-35^{\circ} \mathrm{CA}$ ATDC to form a stratified mixture before ignition [77].

Berntsson et al. [81, 82] investigated the effects of sparkassisted stratified charge HCCI combustion processes. LIF diagnostics on fuel-tracer, formaldehyde, and $\mathrm{OH}$ were conducted on an optical single-cylinder direct-injection SI engine with negative valve overlap (NVO) and low lift to increase the thermal atmosphere to ensure the stable HCCI combustion. They found that the charge inhomogeneity was formed in the cylinder and the fuel injection timing and spark-assisted ignition timings were the primary parameters to affect the HCCI combustion phasing. The hightemperature reactions were influenced by injection timings and spark-assisted ignition timings, indicating different amounts of OH-LIF signals. Based on NVO, spark-assisted ignition, and charge stratification, HCCI combustion phasing could be effectively controlled and the operating range could be extended to lower and higher engine loads.

Musculus [19] investigated the OH-LIF and chemiluminescence of low temperature combustion at the injection timing of $-22^{\circ} \mathrm{CA}$ ATDC. He found that a distinct cool flame could be captured and overlapped with the liquid fuel spray, which would increase the rate of fuel vaporization. Compared to conventional diesel combustion, the $\mathrm{OH}$-LIF distributions were different. For conventional diesel combustion, $\mathrm{OH}$ radicles could only be captured at the periphery of the diesel jet with a thin sheet structure. However, for LTC conditions, $\mathrm{OH}$ radicles could be detected throughout the jet cross section, which demonstrated that there was more complete mixing between liquid jet and ambient air. Furthermore, once autoignition occurred, $\mathrm{OH}$ radicle could be detected with broadening distributions, which demonstrated that the LTC process should be the volumetric autoignition and combustion, rather than flame propagation in conventional diesel combustion.

Above studies show that the formaldehyde and $\mathrm{OH}$ are good markers of the HCCI combustion process at low temperature and high temperature reactions, respectively. Furthermore, the distribution of $\mathrm{OH}$ and formaldehyde is never in the same regions even if both of them can be detected simultaneously at a relatively long period. The timing of formaldehyde formation is unaffected by the EGR level, but the formaldehyde lifetime and the degree of homogeneity and subsequent high temperature ignition are influenced by EGR level. For a given EGR rate, a split injection strategy results in the charge stratification and prolongs the $\mathrm{HCHO}$ lifetime. Furthermore, the rising rate of formaldehyde-LIF intensity is more quickly under homogeneous conditions than that of stratified conditions. OH distributions in HCCI and LTC combustion processes are more broad than that of conventional gasoline spark-ignition or diesel compressionignition, which indicates that the whole combustion should be more close to volumetric combustion rather than flame propagation. Therefore, the LIF diagnostics are a quite 
effective method to reveal the HCCI and LTC combustion process with high spatial distributions.

\section{Optical Diagnostics for Emissions Evolution}

Due to the very low emissions of $\mathrm{NO}_{x}$ and soot for HCCI combustion with port-injection or early-injection due to the quite homogeneous charge, the researches on emissions are very limited. But if the fuel stratification is introduced by late direct-injection, the emissions of $\mathrm{NO}_{x}$ and soot will increase. So, the study on $\mathrm{NO}_{x}$ and soot formation process is necessary to reduce them in new combustion modes. In this section, optical researches on these emissions mainly focus on the NO and soot.

4.1. $\mathrm{NO}_{x}$ Optical Diagnostics on HCCI and LTC. The spectroscopic structure of the NO molecule permits a number of excitation detection strategies and some of them have been utilized in engines. However, all of these strategies are more or less susceptible to the interference from oxygen [83], $\mathrm{PAH}$, and $\mathrm{CO}_{2}$ [84]. Also, all techniques in varying degrees are the absorption of laser and signal light mainly by hot $\mathrm{CO}_{2}$ and $\mathrm{H}_{2} \mathrm{O}$ [85]. Furthermore, the signal is dependent on pressure, temperature, and burned gas composition. Advantages and disadvantages of different excitation/detection strategies have been discussed extensively in a series of publications [86-88].

NO-LIF images have been developed and applied over the last decade in conventional CI or SI engines and GDI engines by many researchers [88-91]. These researches developed the theory of the NO formation. For example, Dec and Canaan [88] investigated the NO-LIF in a conventional diesel engine and found that NO was not produced by the initial premixed combustion which was fuel-rich but began around the jet periphery just after the diffusion flame formed. Then, NO formation increased progressively and NO was still confined to the jet periphery until the jet structure started to disappear toward the end of heat releases. After that, the LIF signals could also be captured until the end of heat releases, which demonstrated that $\mathrm{NO}$ formation continued in hot postcombustion gases. However, in new clean combustion modes, $\mathrm{NO}$ emissions are very low due to the quite low combustion temperature, which restricts NO formation. Therefore, there is little research on the NO-LIF in an HCCI combustion processes.

Zilwa and Steeper $[92,93]$ predicted the emissions of $\mathrm{CO}_{2}, \mathrm{CO}, \mathrm{HC}$, and $\mathrm{NO}_{x}$ from HCCI engines using LIF fuel-distribution measurements. The method is based on the simplifying premise that each individual fuel-air packet burnt as if in a homogeneous mixture at the same equivalence ratio. The relative success of the prediction method indicated a strong correlation between in-cylinder charge distribution and engine emissions. In particular it encouraged the formulation of ideal fuel distributions to guide the development of advanced charge-preparation strategies in HCCI and LTC modes.

4.2. Soot Optical Diagnostics on HCCI and LTC. Due to the sufficient premixed combustion, the soot emission in HCCI

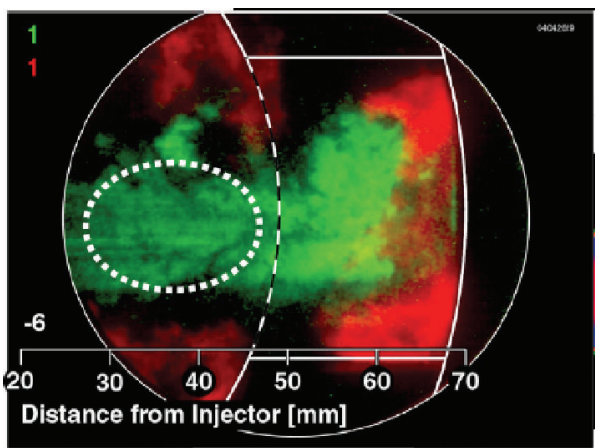

FIGURE 19: OH (green, OH-PLIF) throughout jet cross section, with soot (red, soot luminosity) only at head of jet [19].

can be negligible. But, once the charge stratification was introduced in HCCI, the soot emission will not be neglected in some operation conditions. In this section, the focus will be the soot formation in the new combustion mode, especially for the PCCI and LTC.

Singh et al. [94] and Huestis et al. [95] investigated the soot formation and oxidation processes by two-color pyrometry in LTC conditions. Nitrogen gas was used to achieve lower oxygen concentration and different injection strategies including early-injection, late-injection, and double-injection were tested. They all found that the soot thermometry and luminosity images of LTC were lower than that of conventional high temperature combustion. Soot temperatures measured by two-color pyrometry were near to the adiabatic flame temperatures under LTC conditions. The amount of peak soot volume of late- and double-injection was about 1.5 times higher than that of early-injection. For LTC conditions, there was enough time available for diesel fuel to penetrate and mix with the ambient air, and thus sooting combustion occurred mainly near the edge of the bowl. However, soot was formed farther upstream in the fuel jet under high temperature combustion conditions.

Musculus [19] investigated the soot luminosity and soot laser-induced incandescence of low temperature combustion at the injection timing of $-22^{\circ} \mathrm{CA}$ ATDC. He found that the soot formation was only captured in regions without $\mathrm{OH}$ radicles, and thus soot and $\mathrm{OH}$ should not lie in the same regions. The soot-LII and OH-LIF in conventional diesel combustion have shown that $\mathrm{OH}$ radicles could only be captured at the periphery of the diesel jet or the soot cloud with a thin sheet structure at the earlier combustion stage $[96,97]$, as shown in Figure 19. After that, with the progress of combustion, the OH-LIF could be captured with broad distribution, but regions between soot and $\mathrm{OH}$ did not overlap spatially [98]. That is to say, $\mathrm{OH}$ and soot generally did not persist within the same regions. Both soot luminosity and soot-LII images all showed that the soot is first observed far downstream of the spray jet but located at the head of the spray jet near the cylinder liner. As the spray jet continued to penetrate and develop in the cylinder, the sootLII were mainly located at either "side" of the jet, which was called "head vortex" for spray jet, as shown in Figure 19. 


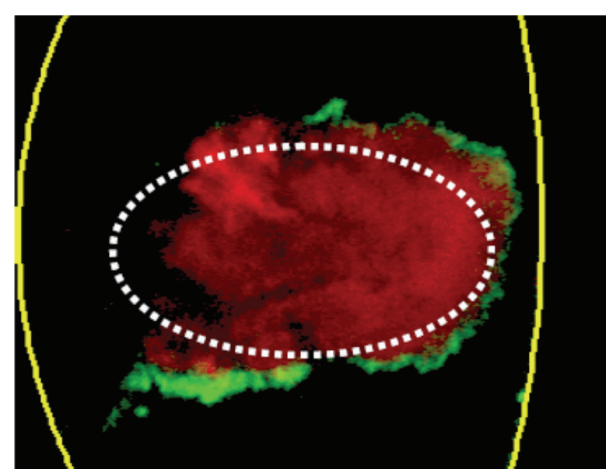

FIGURE 20: OH (green, OH-PLIF) in thin envelope surrounding soot (red, soot LII) throughout the jet cross section [27].

Indeed, even if soot-LII could be captured upstream spray, which should be attributed to the impingement of sooting jets, rather than formed by upstream spray jets. Therefore, the soot formation regions and distributions are different between LTC and conventional diesel combustion where soot is formed farther upstream and throughout the jet cross section [27, 99], as shown in Figure 20. Furthermore, soot was still formed in regions of head vortex for conventional diesel combustion. Thus, it can be concluded that the upstream soot formation has been eliminated for new LTC modes compared with conventional diesel combustion conditions. The same upstream regions have been shown as the white dotted circle in Figures 19 and 20. And, the soot formation reduction in the regions of head vortex is still a large challenge even if aiming to a relative longer premixed low temperature combustion process.

Liu et al. [68, 73, 74] quantitatively investigated the soot concentration by forward illumination light extinction with a copper vapor laser under both conventional diesel combustion and LTC conditions. Meanwhile, the soot models have been improved to understand the soot evolution $[75,100]$. They found that compared with $21 \%$ oxygen concentration, both rates of soot formation and oxidation were increased simultaneously at $18 \%$ oxygen; however the higher soot formation rate resulted in the higher soot mass in the combustion process. At $15 \%$ oxygen concentration, both rates of soot formation and oxidation were reduced simultaneously; however the soot mass in the combustion process were increased further and the reason should be caused by suppressed soot oxidation rates. With the further decrease of oxygen concentrations, the soot formation was suppressed dramatically and thus the soot emissions were reduced. At $1000 \mathrm{~K}$, the soot mass was increased with the decline of oxygen concentrations, which should be derived from the increased regions of high equivalence ratios and the increased acetylene and soot precursors formation at lower ambient oxygen concentration. At $800 \mathrm{~K}$ ambient temperature, however, the soot mass was decreased with the decline of oxygen concentrations, which should be caused by reduced regions of high equivalence ratios and by reduced acetylene and soot precursors formation. The soot distributions have been shown in Figures 13 and 14. Therefore, the authors concluded that soot formation transition from $1000 \mathrm{~K}$ to $800 \mathrm{~K}$ should be the responsible factor for different soot emissions, because of ambient oxygen dilution in conventional and low-temperature flames. The similar studies about ambient temperatures and oxygen concentrations have also been conducted by Zhang et al. [101, 102] by two-color pyrometry and soot luminosity.

These optical diagnostics have presented the distribution and mass concentration for soot emissions in LTC modes. Unlike the conventional diesel combustion which forms soot just downstream of the liquid spray and throughout the jet cross section, the soot formation in LTC is much farther downstream of the liquid spray and only at the head of the jet, in the head vortex or near the edge of the bowl. Furthermore, even if the combustion temperature are not low as shown in Figure 13, the soot distributions are still concentrated on farther downstream of liquid spray and near the chamber wall regions. Therefore, it can be concluded that soot specific distributions are caused by quite low oxygen concentrations.

\subsection{Unburned Hydrocarbons and CO Optical Diagnostics} on HCCI and LTC. Although HCCI and LTC can achieve very low emissions of $\mathrm{NO}_{x}$ and soot, they typically have increased emissions unburned hydrocarbons (UHC) and CO. Musculus et al. [4] investigated the overmixing and unburned hydrocarbon emissions in LTC conditions on a heavy-duty optical diesel engine. The equivalence ratio of mixtures near the injector was measured under without combustion conditions by planar laser-Rayleigh scattering in a constant volume combustion chamber and by LIF of a fuel tracer in an optical engine. The optical diagnostic images indicated that the transient ramp-down of the injector produced a lowmomentum spray penetration at the end of injection and thus formed fuel-lean mixture in the upstream region of the spray jet. Furthermore, the fuel-lean mixture continued until the late of that cycle. Therefore, the upstream fuel-lean mixture likely became too lean to achieve complete combustion, thus contributing to UHC emissions under LTC condition.

Ekoto et al. [103, 104] and Petersen et al. [105] investigated the UHC and CO distribution on a light-duty diesel optical engine under both early- and late-injection under LTC conditions. The LIF measurements on equivalence ratios, UHC and CO, all showed that most fuel accumulated on inner bowl during high temperature heat release, but much of them transported into the squish-volume with the motion of reverse squish flows. Then, the lean mixtures combined with high heat transfer losses to the wall suppressed the fuel oxidation in squish regions. Therefore, the main distributions on UHC and CO were captured in squish regions.

It should be noted that there are also a large amount of UHC and CO emissions in HCCI combustion processes and more studies focus on the formaldehyde-LIF measurements and there is little studies on CO distributions in HCCI. This should be due to the HCCI is controlled by chemical kinetics and the UHC and CO evolution can be explained well by chemical reaction mechanism. For LTC conditions, it is not only controlled by chemical kinetics, but also controlled by mixed process between diesel fuel and air. Under LTC conditions, fuel-lean regions that formed during the period 
of ignition delays are likely a significant source of UHC and $\mathrm{CO}$ emissions for EGR-diluted LTC diesel engines.

\section{Summary}

Optical diagnostics is an effective method to understand the chemical reaction processes in homogeneous charge compression ignition and low temperature combustion modes. Based on optical diagnostics, the true mixing, combustion, and emissions can be seen directly. In this paper, the mixing process by port-injection and direct-injection was reviewed firstly. Then, the combustion chemical reaction mechanism was reviewed based on chemiluminescence, directluminosity, and laser diagnostics. Finally, the evolution of pollutant emissions was reviewed including $\mathrm{NO}_{x}$, soot, $\mathrm{UHC}$, and $\mathrm{CO}$. The main summaries are shown as follows.

5.1. Fuel-Air Mixing Process. It can be found that different port-injection strategies also change the degree of homogeneous charge in the cylinder. Even if a high degree of homogeneity can be seen in the cylinder, there is still lying in local inhomogeneous fluctuations caused by cycle-to-cycle variations. The direct-injection strategy has more advantages than that of port-injection for HCCI autoignition control and operating range extending. However, using early directinjection strategy, it helps to form a more uniform airfuel mixture before ignition but fuel can impinge on the piston head or the cylinder liner and results in wall-wetting and the dilution of oil, which restricts the application of early-injection to some extent. By dual-fuel injection, the stratification on charge and fuel reactivity can be achieved flexibly even if it needs one more fuel tank.

5.2. Combustion Chemical Reaction Processes. It can be found that the HCCI combustion process can be described as follows. At low temperature heat release, a homogeneous weak light can be observed throughout the chamber, which is caused by the formaldehyde chemiluminescence. At high temperature heat release, more strong luminosity derived mainly from $\mathrm{CO}-\mathrm{O}$ continuum and $\mathrm{OH}$ is a mark of the start of high temperature reaction. Between LTHR and HTHR, no luminosity can be captured. Both charge and thermal stratifications can reduce maximum heat release rates and pressure rise rates and thus may extend HCCI operating range. Optical diagnostics shows that the combination between port-injection and direct injection or two-stage direct-injection in the cylinder is effective technological measures to achieve charge stratification. Changes of the intake and coolant temperatures can form temperature or thermal stratification and affect the combustion chemiluminescence, but this method is very hard to achieve in a real engine. A specific piston geometry will also form different turbulence intensity and thus generates the temperature inhomogeneity. For low temperature combustion, the combustion flame with larger distribution is located near to cylinder wall, which means that the flame lift-off is larger than that of conventional diesel combustion.
Although the chemiluminescence or natural-luminosity images present a good time-resolved combustion process in HCCI and LTC, they only provide the results of lineof-sight and without presenting the spatial distributions. Therefore, laser induced fluorescence is used to give spatial distributions on combustion processes and results show that the formaldehyde and $\mathrm{OH}$ are good markers of the HCCI combustion process at low temperature and high temperature reactions, respectively. Furthermore, the distribution of $\mathrm{OH}$ and formaldehyde is never in the same regions even if both of them can be detected simultaneously at a relatively long period. The timing of formaldehyde formation is unaffected by the EGR level, but the formaldehyde lifetime and the degree of homogeneity, and subsequent high temperature ignition are influenced by EGR level. For a given EGR rate, a split injection strategy results in the charge stratification and prolongs the $\mathrm{HCHO}$ lifetime. Furthermore, the rising rate of formaldehyde-LIF intensity is more quickly under homogeneous conditions than that of stratified conditions. $\mathrm{OH}$ distributions in HCCI and LTC combustion processes are more broad than that of conventional gasoline sparkignition or diesel compression-ignition, which indicates that the whole combustion should be more close to volumetric combustion rather than flame propagation.

5.3. Emission Evolution Processes. In HCCI and LTC, NO emissions are very low due to the quite low combustion temperature, which restricts NO formation. Therefore, there is little research on the NO-LIF in an HCCI and LTC combustion processes. There are little studies on soot evolution in HCCI due to the nearly zero soot emissions. In LTC conditions, the soot formation is much farther downstream of the liquid spray and only at the head of the jet, in the head vortex or near the edge of the bowl. Furthermore, even if the combustion temperature is not low, the soot distributions are still concentrated on farther downstream of liquid spray and near the chamber wall regions. Therefore, it can be concluded that soot specific distributions in LTC conditions are caused by quite low oxygen concentrations. There are also a large amount of UHC and CO emissions in HCCI combustion processes and some studies focus on the formaldehyde-LIF measurements to represent UHC distribution in the late cycle. But there are little studies on CO distributions in HCCI, which should be due to the fact that HCCI is controlled by chemical kinetics and the UHC and CO evolution can be explained well by chemical reaction mechanism. For LTC conditions, it is not only controlled by chemical kinetics but also controlled by mixed process between diesel fuel and air. Under LTC conditions, fuel-lean regions that formed during the period of ignition delays are likely a significant source of UHC and CO emissions for EGR-diluted LTC diesel engines.

5.4. Future Direction. Based on previous works reviews, it can be found that there are some shortcomings in HCCI and LTC chemical reaction processes with optical diagnostics.

Firstly, more intermediate species are needed to be measured. In current studies, the main measured intermediate species include formaldehyde, $\mathrm{OH}$, and $\mathrm{CO}$. Meantime, the 
polycyclic aromatics hydrocarbons (PAHs) and $\mathrm{H}_{2} \mathrm{O}_{2}$ have been captured in the cylinder $[19,106]$ or has the potential to distinguish PAHs of different rings [107] even if the study works are limited. Obviously, more intermediate species are detected and more detailed combustion reaction mechanism will be revealed. Therefore, other intermediate species, such as $\mathrm{CH}, \mathrm{NO}$, and PAHs with different rings, are needed to be detected in future to further understand the HCCI and LTC.

Secondly, high-speed and simultaneous multi-species measurements are needed to improve in future. In current studies, high-speed measurements only focus on chemiluminescence or natural luminosity, but these optical diagnostics have low spatial resolution. However, as using laser diagnostics, it has high spatial resolution but low time resolution. Therefore, the combination between high time and spatial resolution to detect the combustion process is the development direction in future for HCCI and LTC. Meanwhile, the optical diagnostics in HCCI and LTC need to capture more species in the same engine cycle. For example, the simultaneous measurements on formaldehyde, $\mathrm{OH}$, PAHs, and soot will give more detailed and complete mechanism on combustion chemical reaction.

Thirdly, the combustion processes in HCCI and LTC mode are primary controlled by chemical kinetics, and thus a large amount of studies are aiming to propose different chemical kinetic reaction mechanism. However, there is little attention on effects of flow or turbulence on combustion processes. For HCCI, even if it is a homogeneous combustion, there is still inhomogeneous charge in local area; therefore how the turbulence affects the local combustion is still an open question. The same question also lies in the LTC conditions. Furthermore, the mixing process has larger effect on LTC processes compared with HCCI conditions; therefore some recent studies have published some works on effects of turbulence on combustion and emissions by Wang et al. [108] and Perini et al. [109]. Obviously, more detailed measurements especially on local turbulence are necessary to clarify the effect of turbulence.

\section{Conflict of Interests}

The authors declare that there is no conflict of interests regarding the publication of this paper.

\section{Acknowledgment}

The authors would like to acknowledge the financial supports to the research provided by National Basic Research Program of China (973 Program) through its Project of 2013 CB228402.

\section{References}

[1] M. Noguchi, Y. Tanaka, T. Tanaka, and Y. Takeuchi, "A study on gasoline engine combustion by observation of intermediate reactive products during combustion," SAE Paper 790840, 1979.

[2] M. Yao, Z. Zheng, and H. Liu, "Progress and recent trends in homogeneous charge compression ignition (HCCI) engines,"
Progress in Energy and Combustion Science, vol. 35, no. 5, pp. 398-437, 2009.

[3] J. E. Dec, "Advanced compression-ignition engines-understanding the in-cylinder processes," Proceedings of the Combustion Institute, vol. 32, pp. 2727-2742, 2009.

[4] M. P. B. Musculus, P. C. Miles, and L. M. Pickett, "Conceptual models for partially premixed low-temperature diesel combustion," Progress in Energy and Combustion Science, vol. 39, no. 2-3, pp. 246-283, 2013.

[5] N. P. Komninos and C. D. Rakopoulos, "Modeling HCCI combustion of biofuels: a review," Renewable \& Sustainable Energy Reviews, vol. 16, no. 3, pp. 1588-1610, 2012.

[6] M. Richter, J. Engström, A. Franke, M. Aldén, A. Hultqvist, and B. Johansson, "The influence of charge inhomogeneity on the HCCI combustion process," SAE Paper 2000-01-2868, 2000.

[7] M. Richter, A. Franke, M. Aldén, A. Hultqvist, and B. Johansson, "Optical diagnostics applied to a naturally aspirated homogeneous charge compression ignition engine," SAE Paper 1999-013649, 1999.

[8] K. Kumano, Y. Yamasaki, and N. Iida, "An investigation of the effect of charge inhomogeneity on the ignition and combustion processes in a HCCI engine using chemiluminescence imaging," Journal of Thermal Science \& Technology, vol. 2, no. 2, pp. 200-211, 2007.

[9] J. Kodavasal, D. N. Assanis, G. A. Lavoie, and J. B. Martz, "The effects of thermal and compositional stratification on the ignition and duration of homogeneous charge compression ignition combustion," Combustion \& Flame, vol. 162, no. 2, pp. 451-461, 2015.

[10] D. Dahl, M. Andersson, and I. Denbratt, "The role of charge stratification for reducing ringing in gasoline engine homogeneous charge compression ignition combustion investigated by optical imaging," International Journal of Engine Research, vol. 14, no. 5, pp. 525-536, 2013.

[11] A. Krisman, E. R. Hawkes, S. Kook, M. Sjöberg, and J. E. Dec, "On the potential of ethanol fuel stratification to extend the high load limit in stratified-charge compression-ignition engines," Fuel, vol. 99, no. 9, pp. 45-54, 2012.

[12] C. H. Lee and K. H. Lee, "An experimental study of the combustion characteristics in SCCI and CAI based on directinjection gasoline engine," Experimental Thermal and Fluid Science, vol. 31, no. 8, pp. 1121-1132, 2007.

[13] C. S. Lee, K. H. Lee, and D. S. Kim, "Experimental and numerical study on the combustion characteristics of partially premixed charge compression ignition engine with dual fuel," Fuel, vol. 82, no. 5, pp. 553-560, 2003.

[14] M. Y. Kim, J. H. Lee, and C. S. Lee, "Combustion characteristics and $\mathrm{NO}_{x}$ emissions of a dimethyl-ether-fueled premixed charge compression ignition engine," Energy and Fuels, vol. 22, no. 6, pp. 4206-4212, 2008.

[15] M. Jia, M. Xie, H. Liu, W.-H. Lam, and T. Wang, "Numerical simulation of cavitation in the conical-spray nozzle for diesel premixed charge compression ignition engines," Fuel, vol. 90, no. 8, pp. 2652-2661, 2011.

[16] S. Choi and K. Min, "Analysis of the combustion and emissions of a diesel engine in early-injection, partially-premixed charge compression ignition regimes," Proceedings of the Institution of Mechanical Engineers, Part D: Journal of Automobile Engineering, vol. 227, no. 7, pp. 939-950, 2013.

[17] H. Kim, K. Kim, and K. Lee, "Reduction in harmful emissions using a two-stage injection-type premixed charge compression 
ignition engine," Environmental Engineering Science, vol. 26, no. 11, pp. 1567-1576, 2009.

[18] H. Kim, J. Lee, K. Kim, and K. Lee, "Effect of the atkinson cycle combined with calibration factors on a two-stage injectiontype premixed charge compression ignition engine," Energy and Fuels, vol. 23, no. 10, pp. 4908-4916, 2009.

[19] M. P. B. Musculus, "Multiple simultaneous optical diagnostic imaging of early-injection low-temperature combustion in a heavy-duty diesel engine," SAE Paper 2006-01-0079, 2006.

[20] K. Akihama, Y. Takatori, K. Inagaki, S. Sasaki, and A. M. Dean, "Mechanism of the smokeless rich diesel combustion by reducing temperature," SAE Transactions, vol. 110, no. 3, pp. 648-662, 2001.

[21] T. Lachaux and M. P. B. Musculus, "In-cylinder unburned hydrocarbon visualization during low-temperature compression-ignition engine combustion using formaldehyde PLIF," Proceedings of the Combustion Institute, vol. 31, no. 2, pp. 2921-2929, 2007.

[22] A. S. Cheng, B. T. Fisher, G. C. Martin, and C. J. Mueller, "Effects of fuel volatility on early direct-injection, low-temperature combustion in an optical diesel engine," Energy \& Fuels, vol. 24, no. 3, pp. 1538-1551, 2010.

[23] T. Fang, R. E. Coverdill, C.-F. F. Lee, and R. A. White, "Lowtemperature combustion within a HSDI diesel engine using multiple-injection strategies," Transactions of the Asme-Journal of Engineering for Gas Turbines and Power, vol. 131, no. 6, Article ID 062803, 2009.

[24] T. Fang, Y.-C. Lin, M. F. Tien, and C.-F. Lee, "Reducing $\mathrm{NO}_{x}$ emissions from a biodiesel-fueled engine by use of lowtemperature combustion," Environmental Science \& Technology, vol. 42, no. 23, pp. 8865-8870, 2008.

[25] H. Liu, J. Xu, Z. Zheng, S. Li, and M. Yao, "Effects of fuel properties on combustion and emissions under both conventional and low temperature combustion mode fueling 2,5dimethylfuran/diesel blends," Energy, vol. 62, pp. 215-223, 2013.

[26] H. Liu, S. Li, Z. Zheng, J. Xu, and M. Yao, "Effects of n-butanol, 2-butanol, and methyl octynoate addition to diesel fuel on combustion and emissions over a wide range of exhaust gas recirculation (EGR) rates," Applied Energy, vol. 112, pp. 246-256, 2013.

[27] J. E. Dec, "A conceptual model of D.I. diesel combustion based on laser-sheet imaging," SAE Transactions, vol. 106, no. 3, pp. 1319-1348, 1997.

[28] C. Espey, J. E. Dec, and T. A. Litzinger, "Quantitative 2-D fuel vapor concentration imaging in a firing D.I. diesel engine using planar laser-induced Rayleigh scattering," SAE Transactions, vol. 103, no. 3, pp. 1145-1160, 1994.

[29] J. T. Kashdan, N. Docquier, and G. Bruneaux, "Mixture preparation and combustion via LIEF and LIF of combustion radicals in a direct-injection HCCI diesel engine," SAE Paper 2004-012945, 2004.

[30] T.-G. Fang, R. E. Coverdill, C.-F. F. Lee, and R. A. White, "Effect of the injection angle on liquid spray development in a high-speed direct-injection optical diesel engine," Proceedings of the Institution of Mechanical Engineers, Part D: Journal of Automobile Engineering, vol. 223, no. 8, pp. 1077-1092, 2009.

[31] T. Fang, R. E. Coverdill, C.-F. F. Lee, and R. A. White, "Effects of injection angles on combustion processes using multiple injection strategies in an HSDI diesel engine," Fuel, vol. 87, no. 15-16, pp. 3232-3239, 2008.
[32] T. Fang and C.-F. F. Lee, "Low sooting combustion of narrowangle wall-guided sprays in an HSDI diesel engine with retarded injection timings," Fuel, vol. 90, no. 4, pp. 1449-1456, 2011.

[33] H. Liu, S. Ma, Z. Zhang, Z. Zheng, and M. Yao, "Study of the control strategies on soot reduction under early-injection conditions on a diesel engine," Fuel, vol. 139, pp. 472-481, 2015.

[34] R. Kiplimo, E. Tomita, N. Kawahara, and S. Yokobe, "Effects of spray impingement, injection parameters, and EGR on the combustion and emission characteristics of a PCCI diesel engine," Applied Thermal Engineering, vol. 37, pp. 165-175, 2012.

[35] R. R. Steeper and S. de Zilwa, "Improving the $\mathrm{NOX}-\mathrm{CO}_{2}$ trade-off of an HCCI engine using a multi-hole injector," SAE Technical Paper 2007-01-0180, 2007.

[36] H. Liu, M. Huo, Y. Liu et al., "Time-resolved spray, flame, soot quantitative measurement fueling n-butanol and soybean biodiesel in a constant volume chamber under various ambient temperatures," Fuel, vol. 133, pp. 317-325, 2014.

[37] S. Kokjohn, R. Reitz, D. Splitter, and M. Musculus, "Investigation of fuel reactivity stratification for controlling PCI heatrelease rates using high-speed chemiluminescence imaging and fuel tracer fluorescence," SAE Technical Papers, vol. 5, no. 2, pp. 248-269, 2012.

[38] Z. Chen, M. Yao, Z. Zheng, and Q. Zhang, "Experimental and numerical study of methanol/dimethyl ether dual-fuel compound combustion," Energy and Fuels, vol. 23, no. 5, pp. 2719-2730, 2009.

[39] S. Ma, Z. Zheng, H. Liu, Q. Zhang, and M. Yao, "Experimental investigation of the effects of diesel injection strategy on gasoline/diesel dual-fuel combustion," Applied Energy, vol. 109, no. 2, pp. 202-212, 2013.

[40] H. Liu, X. Wang, Z. Zheng, J. Gu, H. Wang, and M. Yao, "Experimental and simulation investigation of the combustion characteristics and emissions using n-butanol/biodiesel dualfuel injection on a diesel engine," Energy, vol. 74, pp. 741-752, 2014.

[41] S. L. Kokjohn, R. M. Hanson, D. A. Splitter, and R. D. Reitz, "Fuel reactivity controlled compression ignition (RCCI): a pathway to controlled high-efficiency clean combustion," International Journal of Engine Research, vol. 12, no. 3, pp. 209-226, 2011.

[42] X. Lu, J. Ma, L. Ji, and Z. Huang, "Simultaneous reduction of $\mathrm{NO}_{x}$ emission and smoke opacity of biodiesel-fueled engines by port injection of ethanol," Fuel, vol. 87, no. 7, pp. 1289-1296, 2008.

[43] Y. J. Kim, K. B. Kim, and K. H. Lee, "Effect of a 2-stage injection strategy on the combustion and flame characteristics in a PCCI engine," International Journal of Automotive Technology, vol. 12, no. 5, pp. 639-644, 2011.

[44] W. H. Su and W. B. Yu, "Effects of mixing and chemical parameters on thermal efficiency in a partly premixed combustion diesel engine with near-zero emissions," International Journal of Engine Research, vol. 13, no. 3, pp. 188-198, 2012.

[45] X. G. Wang, Z. H. Huang, O. A. Kuti, W. Zhang, and K. Nishida, "An experimental investigation on spray, ignition and combustion characteristics of biodiesels," Proceedings of the Combustion Institute, vol. 33, no. 2, pp. 2071-2077, 2011.

[46] X. G. Wang, Z. H. Huang, W. Zhang, O. A. Kuti, and K. Nishida, "Effects of ultra-high injection pressure and micro-hole nozzle on flame structure and soot formation of impinging diesel spray," Applied Energy, vol. 88, no. 5, pp. 1620-1628, 2011.

[47] I. Glassman, Combustion, Academic Press, New York, NY, USA, 3rd edition, 1996. 
[48] J. E. Dec and C. Espey, "Chemiluminescence imaging of autoignition in a DI diesel engine," SAE Technical Paper 982685, 1998.

[49] A. G. Gaydon, The Spectroscopy of Flames, Chapman \& Sons, 2nd edition, 1974.

[50] A. Hultqvist, M. Christensen, B. Johansson, A. Franke, M. Richter, and M. Aldén, "A study of the homogeneous charge compression ignition combustion process by chemiluminescence imaging," SAE Paper 1999-01-3680, 1999.

[51] B. Kim, M. Kaneko, Y. Ikeda, and T. Nakajima, "Detailed spectral analysis of the process of HCCI combustion," Proceedings of the Combustion Institute, vol. 29, no. 1, pp. 671-677, 2002.

[52] R. Augusta, D. E. Foster, J. B. Ghandhi, J. Eng, and P. M. Najt, "Chemiluminescence measurements of homogeneous charge compression ignition (HCCI) combustion," SAE Paper 2006-011520, 2006.

[53] H.-F. Liu, M.-F. Yao, C. Jin, P. Zhang, Z.-M. Li, and Z.-Q. Zheng, "Chemiluminescence spectroscopic analysis of homogeneous charge compression ignition combustion processes," Spectroscopy and Spectral Analysis, vol. 30, no. 10, pp. 2611-2615, 2010.

[54] E. Murase, K. Hanada, T. Miyaura, and J. Ikeda, "Photographic observation and emission spectral analysis of homogeneous charge compression ignition combustion," Combustion Science and Technology, vol. 177, no. 9, pp. 1699-1723, 2005.

[55] E. Mancaruso and B. M. Vaglieco, "Optical investigation of the combustion behaviour inside the engine operating in HCCI mode and using alternative diesel fuel," Experimental Thermal \& Fluid Science, vol. 34, no. 3, pp. 346-351, 2010.

[56] J. E. Dec, W. Hwang, and M. Sjöberg, "An investigation of thermal stratification in HCCI engines using chemiluminescence imaging," SAE Technical Paper 2006-01-1518, 2006.

[57] W. Hwang, J. Dec, and M. Sjöberg, "Spectroscopic and chemical-kinetic analysis of the phases of HCCI autoignition and combustion for single- and two-stage ignition fuels," Combustion \& Flame, vol. 154, no. 3, pp. 387-409, 2008.

[58] J. B. Heywood, Internal Combustion Engine Fundamentals, McGraw-Hill, New York, NY, USA, 1988.

[59] N. Peters, Turbulent Combustion, Cambridge Monographs on Mechanics, Cambridge University Press, Cambridge, UK, 2000.

[60] A. Hultqvist, M. Christensen, B. Johansson et al., "The HCCI combustion process in a single cycle-high-speed fuel tracer LIF and chemiluminescence imaging," SAE Paper 2002-01-0424, SAE International, 2002.

[61] A. Vressner, A. Hultqvist, and B. Johansson, "Study on the combustion chamber geometry effects in an HCCI engine using high-speed cycle-resolved chemiluminescence imaging," SAE Paper 2007-01-0217, 2007.

[62] H. Liu, P. Zhang, Z. Li, J. Luo, Z. Zheng, and M. Yao, "Effects of temperature inhomogeneities on the HCCI combustion in an optical engine," Applied Thermal Engineering, vol. 31, no. 14-15, pp. 2549-2555, 2011.

[63] H. Liu, Z. Zheng, M. Yao, P. Zhang, B. He, and Y. Qi, "Influence of temperature and mixture stratification on HCCI combustion using chemiluminescence images and CFD analysis," Applied Thermal Engineering, vol. 33-34, no. 1, pp. 135-143, 2012.

[64] P. G. Aleiferis, A. G. Charalambides, Y. Hardalupas, A. M. K. P. Taylor, and Y. Urata, "Modelling and experiments of HCCI engine combustion with charge stratification and internal EGR," SAE Paper 2005-01-3725, 2005.

[65] A. W. Berntsson and I. Denbratt, "HCCI combustion using charge stratification for combustion control," SAE Technical Paper 2007-01-0210, 2007.
[66] S. Kook and C. Bae, "Combustion control using two-stage diesel fuel injection in a single-cylinder PCCI engine," SAE Paper 2004-01-0938, 2004.

[67] A. Upatnieks, C. J. Mueller, and G. C. Martin, “The influence of charge-gas dilution and temperature on DI diesel combustion processes using a short-ignition-delay, oxygenated fuel," SAE 2005-01-2088, 2005.

[68] H. Liu, C.-F. F. Lee, M. Huo, and M. Yao, "Combustion characteristics and soot distributions of neat butanol and neat soybean biodiesel," Energy \& Fuels, vol. 25, no. 7, pp. 3192-3203, 2011.

[69] Z. Zheng, L. Yue, H. Liu, Y. Zhu, X. Zhong, and M. Yao, "Effect of two-stage injection on combustion and emissions under high EGR rate on a diesel engine by fueling blends of diesel/gasoline, diesel/n-butanol, diesel/gasoline/n-butanol and pure diesel," Energy Conversion and Management, vol. 90, pp. 111, 2015.

[70] Z. Zheng, C. Li, H. Liu, Y. Zhang, X. Zhong, and M. Yao, "Experimental study on diesel conventional and low temperature combustion by fueling four isomers of butanol," Fuel, vol. 141, pp. 109-119, 2015.

[71] A. Upatnieks and C. J. Mueller, "Controlled DI diesel combustion using dilute, cool charge gas and a short-ignition-delay, oxygenated fuel," SAE Technical Paper 2005-01-0363, 2005.

[72] C. J. Mueller and A. Upatnieks, "Dilute clean diesel combustion achieves low emissions and high efficiency while avoiding control problems of HCCI," in Proceedings of the 11th Annual Diesel Engine Emissions Reduction Conference (DEER '05), Chicago, Ill, USA, August 2005.

[73] H. Liu, X. Bi, M. Huo, C.-F. F. Lee, and M. Yao, "Soot emissions of various oxygenated biofuels in conventional diesel combustion and low temperature combustion conditions," Energy \& Fuels, vol. 26, no. 3, pp. 1900-1911, 2012.

[74] H. Liu, C.-F. Lee, M. Huo, and M. Yao, "Comparison of ethanol and butanol as additives in soybean biodiesel using a constant volume combustion chamber," Energy \& Fuels, vol. 25, no. 4, pp. 1837-1846, 2011.

[75] X. Bi, H. Liu, M. Huo, C. Shen, X. Qiao, and C.-F. F. Lee, "Experimental and numerical study on soot formation and oxidation by using diesel fuel in constant volume chamber with various ambient oxygen concentrations," Energy Conversion and Management, vol. 84, pp. 152-163, 2014.

[76] R. Collin, J. Nygren, M. Richter, M. Aldén, L. Hildingsson, and B. Johansson, "Simultaneous OH- and formaldehyde-LIF measurements in an HCCI engine," SAE Technical Paper 200301-3218, 2003.

[77] G. Särner, M. Richter, M. Aldén, L. Hildingsson, A. Hultqvist, and B. Johansson, "Simultaneous PLIF measurements for visualization of formaldehyde- and fuel-distributions in a DI HCCI engine," SAE Paper 2005-01-3869, 2005.

[78] H. Zhao, Z. Peng, and T. Ma, "Investigation of the HCCI/CAI combustion process by 2-D PLIF imaging of formaldehyde," SAE Paper 2004-01-1901, 2004.

[79] J. T. Kashdan and J. F. Papagni, "LIF imaging of auto-ignition and combustion in a direct-injection, diesel-fuelled HCCI engine," SAE Technical Paper 2005-01-3739, 2005.

[80] L. Hildingsson, H. Persson, B. Johansson et al., "Optical diagnostics of HCCI and UNIBUS using 2-D PLIF of $\mathrm{OH}$ and formaldehyde," SAE Paper 2005-01-0175, 2005.

[81] A. W. Berntsson and I. Denbratt, "Optical study of HCCI combustion using NVO and an SI stratified charge," SAE Paper 2007-24-0012, SAE International, 2007. 
[82] A. W. Berntsson, M. Andersson, D. Dahl, and I. Denbratt, "A LIF-study of $\mathrm{OH}$ in the negative valve overlap of a spark-assisted HCCI combustion engine," SAE Paper 2008-01-0037, 2008.

[83] C. Schulz, J. B. Jeffries, D. F. Davidson, J. D. Koch, J. Wolfrum, and R. K. Hanson, "Impact of UV absorption by $\mathrm{CO}_{2}$ and $\mathrm{H}_{2} \mathrm{O}$ on NO LIF in high-pressure combustion applications," Proceedings of the Combustion Institute, vol. 29, no. 2, pp. 27352742, 2002.

[84] C. Schulz, J. D. Koch, D. F. Davidson, J. B. Jeffries, and R. K. Hanson, "Ultraviolet absorption spectra of shock-heated carbon dioxide and water between 900 and $3050 \mathrm{~K}$," Chemical Physics Letters, vol. 355, no. 1-2, pp. 82-88, 2002.

[85] W. G. Bessler, C. Schulz, T. Lee, J. B. Jeffries, and R. K. Hanson, "Strategies for laser-induced fluorescence detection of nitric oxide in high pressure flames. I. A - X $(0,0)$ excitation," Applied Optics, vol. 41, no. 18, pp. 3547-3557, 2002.

[86] W. G. Bessler, C. Schulz, T. Lee, J. B. Jeffries, and R. K. Hanson, "Strategies for laser-induced fluorescence detection of nitric oxide in high pressure flames. II. A - X $(0,1)$ excitation," Applied Optics, vol. 42, no. 12, pp. 2031-2042, 2003.

[87] W. G. Bessler, C. Schulz, T. Lee, J. B. Jeffries, and R. K. Hanson, "Strategies for laser-induced fluorescence detection of nitric oxide in high-pressure flames. III. Comparison of A-X excitation schemes," Applied Optics, vol. 42, no. 24, pp. 49224936, 2003.

[88] J. E. Dec and R. E. Canaan, "PLIF imaging of NO formation in a DI diesel engine," SAE Technical Paper 980147, 1998.

[89] K. Akihama, T. Fujikawa, and Y. Hattori, "Laser-induced fluorescence imaging of no in a port-fuel-injected, stratifiedcharge SI engine-correlations between $\mathrm{N}$ formation region and stratified fuel distribution," SAE Paper 981430, 1998.

[90] F. Hildenbrand, C. Schulz, J. Wolfrum, F. Keller, and E. Wagner, "Laser diagnostic analysis of NO formation in a direct injection diesel engine with pump-line-nozzle and common rail injection systems," Proceedings of the Combustion Institute, vol. 28, no. 1, pp. 1137-1144, 2000.

[91] W. G. Bessler, M. Hofmann, F. Zimmermann et al., "Quantitative in-cylinder NO-LIF imaging in a realistic gasoline engine with spray-guided direct injection," Proceedings of the Combustion Institute, vol. 30, no. 2, pp. 2667-2674, 2005.

[92] S. D. Zilwa and R. Steeper, "Predicting emissions from HCCI engines using LIF imaging," SAE Paper 2005-01-3747, SAE International, 2005.

[93] S. D. Zilwa and R. Steeper, "Predicting $\mathrm{NO}_{X}$ emissions from HCCI engines using LIF imaging," SAE Paper 2006-01-0025, 2006.

[94] S. Singh, R. D. Reitz, and P. B. M. Mark, "2-color thermometry experiments and high-speed imaging of multi-mode diesel engine combustion," SAE Technical Paper 2005-01-3842, 2005.

[95] E. Huestis, P. A. Erichkson, and M. P. B. Musculus, "In-cylinder and exhaust soot in low-temperature combustion using a widerange of EGR in a heavy-duty diesel engine," SAE Paper 200701-4017, 2007.

[96] J. E. Dec and E. B. Coy, "OH radical imaging in a DI diesel engine and the structure of the early diffusion flame," $S A E$ Transactions, vol. 105, no. 3, pp. 1127-1148, 1996.

[97] J. E. Dec and D. R. Tree, "Diffusion-flame/wall interactions in a heavy-duty DI diesel engine," SAE Transactions, vol. 110, no. 3, pp. 1618-1634, 2001.

[98] J. E. Dec and P. L. Kelly-Zion, "The effects of injection timing and diluent addition on late-combustion soot burnout in a DI diesel engine based on simultaneous 2-D imaging of $\mathrm{OH}$ and soot," SAE Technical Paper 2000-01-0238, 2000.

[99] Q.-L. Tang, P. Zhang, H.-F. Liu, and M.-F. Yao, "Quantitative measurements of soot volume fractions in diesel engine using laser-induced incandescence method," Acta Physico-Chimica Sinica, vol. 31, no. 5, pp. 980-988, 2015.

[100] M. Xiao, H. Liu, X. Bi, H. Wang, and C.-F. F. Lee, "Experimental and numerical investigation on soot behavior of soybean biodiesel under ambient oxygen dilution in conventional and low-temperature flames," Energy and Fuels, vol. 28, no. 4, pp. 2663-2676, 2014.

[101] J. Zhang, W. Jing, W. L. Roberts, and T. Fang, "Effects of ambient oxygen concentration on biodiesel and diesel spray combustion under simulated engine conditions," Energy, vol. 57, pp. 722732, 2013.

[102] J. Zhang, W. Jing, W. L. Roberts, and T. Fang, "Soot temperature and KL factor for biodiesel and diesel spray combustion in a constant volume combustion chamber," Applied Energy, vol. 107, pp. 52-65, 2013.

[103] I. Ekoto, W. Colban, P. Miles, S. Park, and D. E. Foster, "Sources of UHC emissions from a light-duty diesel engine operating in a partially premixed combustion regime," SAE International Journal of Engines, vol. 2, no. 1, pp. 1265-1289, 2009.

[104] I. W. Ekoto, W. F. Colban, P. C. Miles et al., "UHC and CO emissions sources from a light-duty diesel engine undergoing late-injection low-temperature combustion," in Proceedings of the ASME Internal Combustion Engine Division Fall Technical Conference (ICEF '09), Paper no. ICEF2009-14030, pp. 163-172, Lucerne, Switzerland, September 2009.

[105] B. Petersen, P. Miles, and D. Sahoo, "Equivalence ratio distributions in a light-duty diesel engine operating under partially premixed conditions," SAE International Journal of Engines, vol. 5, no. 2, pp. 526-537, 2012.

[106] B. Li, M. Jonsson, M. Algotsson et al., "Quantitative detection of hydrogen peroxide in an HCCI engine using photofragmentation laser-induced fluorescence," Proceedings of the Combustion Institute, vol. 34, no. 2, pp. 3573-3581, 2013.

[107] P. Zhang, H.-F. Liu, B.-L. Chen, Q.-L. Tang, and M.-F. Yao, "Fluorescence spectra of polycyclic aromatic hydrocarbons and soot concentration in partially premixed flames of diesel surrogate containing oxygenated additives," Acta Physico-Chimica Sinica, vol. 31, no. 1, pp. 32-40, 2015

[108] B. L. Wang, C. W. Lee, R. D. Reitz, P. C. Miles, and Z. Han, "A generalized renormalization group turbulence model and its application to a light-duty diesel engine operating in a lowerature combustion regime," International Journal of Engine Research, vol. 14, no. 3, pp. 279-292, 2013.

[109] F. Perini, P. C. Miles, and R. D. Reitz, "A comprehensive modeling study of in-cylinder fluid flows in a high-swirl, lightduty optical diesel engine," Computers \& Fluids, vol. 105, pp. 113124, 2014. 

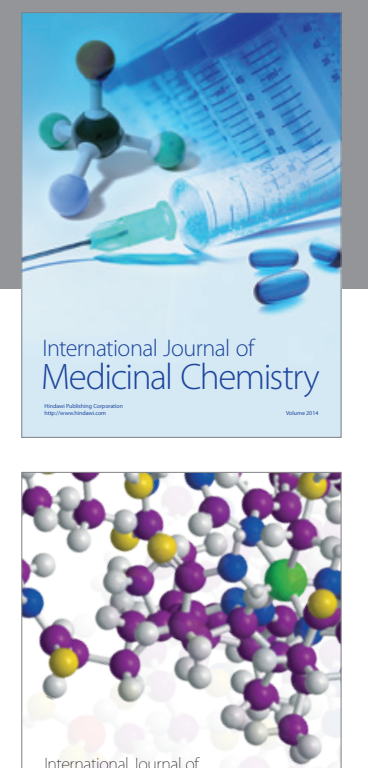

\section{Carbohydrate} Chemistry

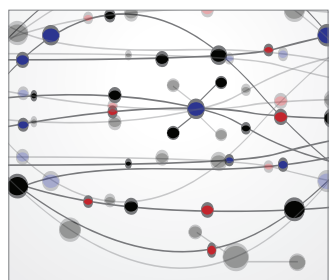

The Scientific World Journal
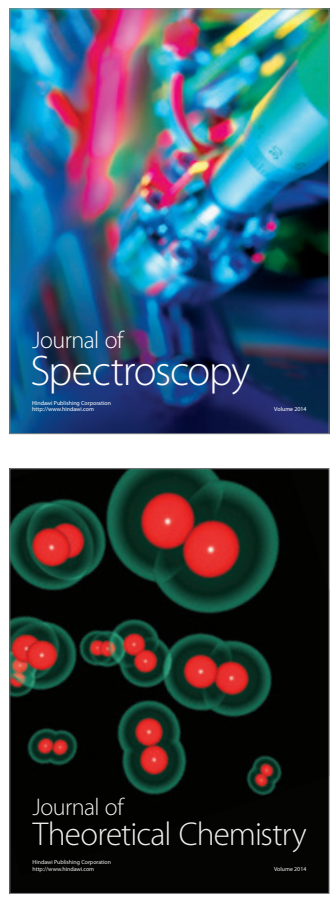
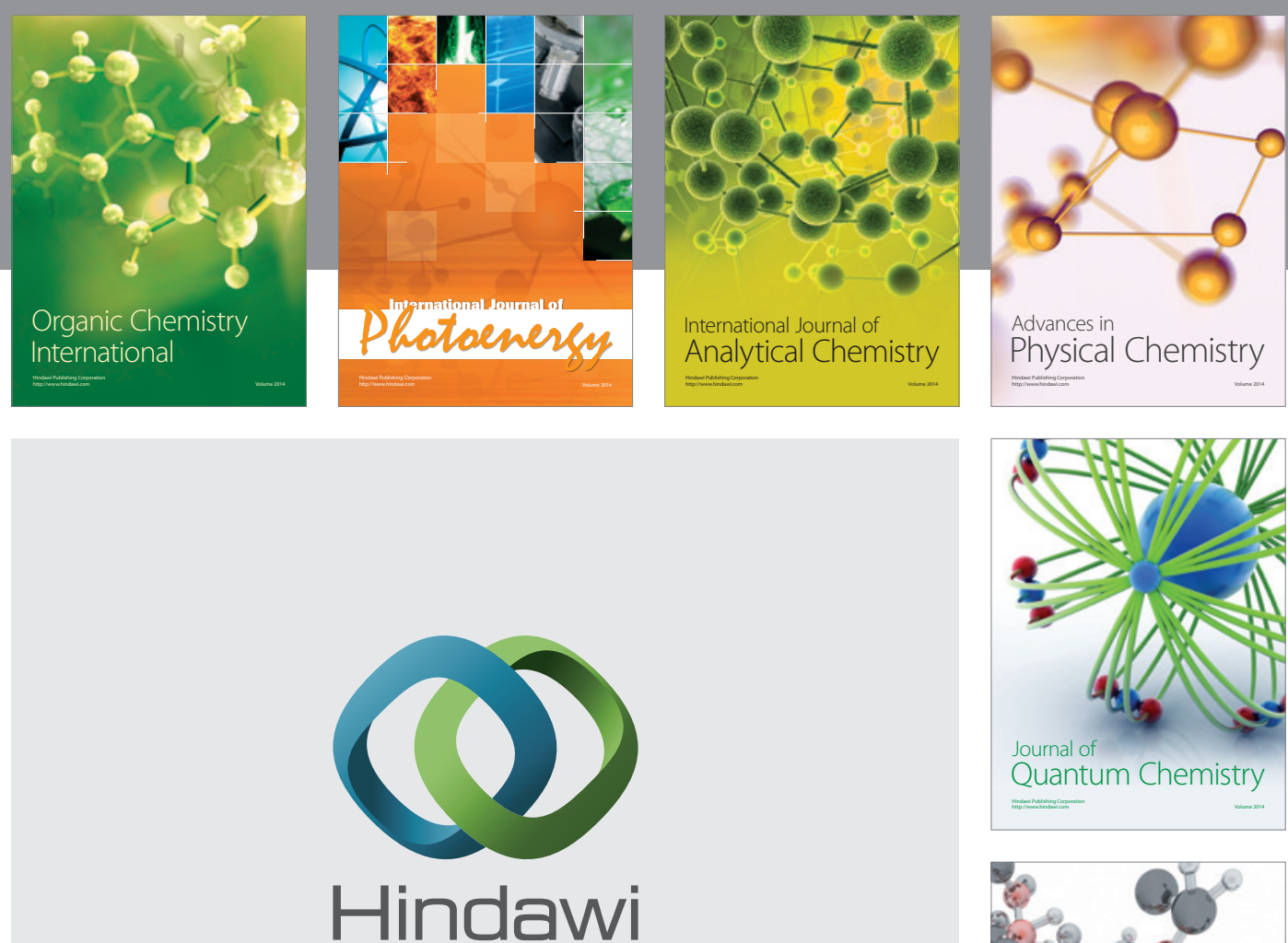

Submit your manuscripts at

http://www.hindawi.com

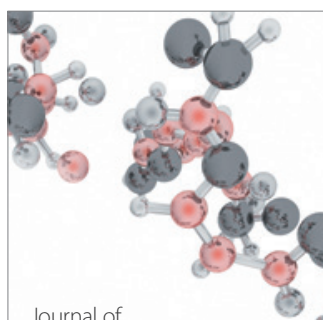

Analytical Methods

in Chemistry

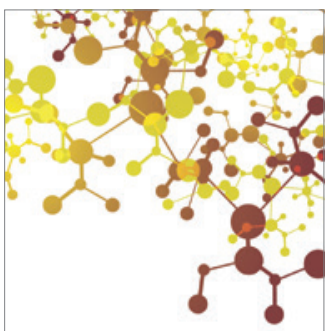

Journal of

Applied Chemistry

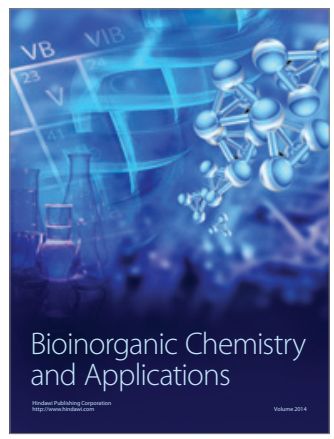

Inorganic Chemistry
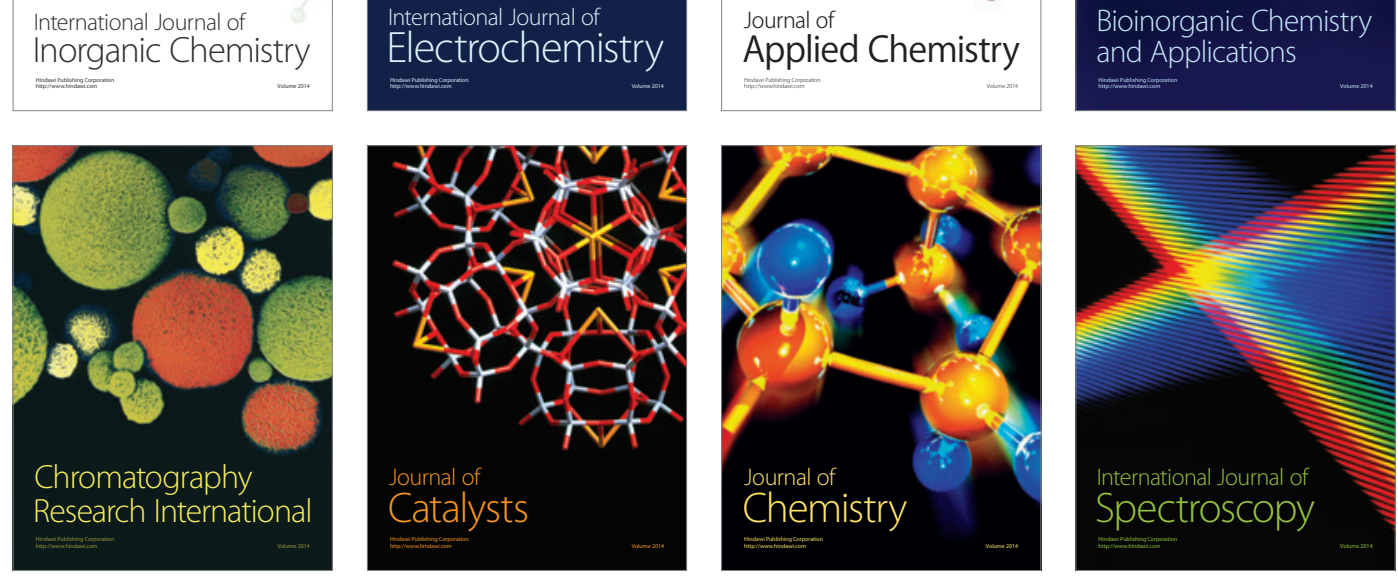